\title{
MicroRNAs for osteosarcoma in the mouse: a meta-analysis
}

\author{
Junli Chang ${ }^{1,2}$, Min Yao ${ }^{1,2}$, Yimian $\mathrm{Li}^{1,2}$, Dongfeng Zhao ${ }^{1,2}$, Shaopu Hu${ }^{1,2}$, Xuejun \\ Cui $^{1,2}$, Gang Liu ${ }^{3}$, Qi Shi ${ }^{1,2}$, Yongjun Wang ${ }^{1,2,4}$ and Yanping Yang ${ }^{1,2}$ \\ ${ }^{1}$ Longhua Hospital, Shanghai University of Traditional Chinese Medicine, Shanghai, China \\ ${ }^{2}$ Spine Institute, Shanghai University of Traditional Chinese Medicine, Shanghai, China \\ ${ }^{3}$ Division of Pulmonary and Critical Care Medicine, Department of Medicine, University of Alabama at Birmingham, \\ Birmingham, AL, USA \\ ${ }^{4}$ School of Rehabilitation Science, Shanghai University of Traditional Chinese Medicine, Shanghai, China \\ Correspondence to: YanpingYang, email: yanpingyangks@163.com
}

Keywords: miRNA; osteosarcoma; meta-analysis; mouse; therapeutic target

Received: January 25, $2016 \quad$ Accepted: September 25, $2016 \quad$ Published: November 12, 2016

\section{ABSTRACT}

Osteosarcoma (OS) is the most common primary malignant bone carcinoma with high morbidity that happens mainly in children and young adults. As the key components of gene-regulatory networks, microRNAs (miRNAs) control many critical pathophysiological processes, including initiation and progression of cancers. The objective of this study is to summarize and evaluate the potential of miRNAs as targets for prevention and treatment of OS in mouse models, and to explore the methodological quality of current studies. We searched PubMed, Web of Science, Embase, Wan Fang Database, VIP Database, China Knowledge Resource Integrated Database, and Chinese BioMedical since their beginning date to 10 May 2016. Two reviewers separately screened the controlled studies, which estimate the effects of miRNAs on osteosarcoma in mice. A pair-wise analysis was performed. Thirty six studies with enough randomization were selected and included in the meta-analysis. We found that blocking oncogenic or restoring decreased miRNAs in cancer cells could significantly suppress the progression of OS in vivo, as assessed by tumor volume and tumor weight. This meta-analysis suggests that miRNAs are potential therapeutic targets for OS and correction of the altered expression of miRNAs significantly suppresses the progression of OS in mouse models, however, the overall methodological quality of studies included here was low, and more animal studies with the rigourous design must be carried out before a miRNA-based treatment could be translated from animal studies to clinical trials.

\section{INTRODUCTION}

Osteosarcoma (OS), is a most frequent primary malignant bone tumor, accounts for $60 \%$ of all malignant childhood bone tumors, and is the second highest reason of cancer-associated death in adolescents [1,2]. Although OS can happen in any bone, the most common sites of primary bone malignancies are the proximal tibia, proximal humerus and distal femur [1]. Typical symptoms and signs include pain history, localized swelling, joint movement limitations and typical findings of normal trabecular bone destruction on X-rays [3, 4].

Despite the neoadjuvant therapeutic strategies combined with aggressive tumor resection, the prognosis for OS patients still remains poor due to the risk of local relapse and development of pulmonary metastasis $[5,6]$.
For all the children diagnosed with OS, only $70 \%$ of them will survive beyond 5 years; less than $50 \%$ of them will live for more than 10 years [7-9]. Therefore, the clinical need for developing the new therapeutic approaches targeting the treatment of OS remains urgent but unmet.

MiRNAs are a class of non-coding RNAs containing about 22 nucleotides and can regulate the expression of more than $30 \%$ of all genes by imperfect base pairing with 3 '-untranslated region (3'-UTR) of the target mRNAs at post-transcriptional level $[10,11]$. Growing evidences show that abnormal miRNA expression has been detected in almost all human cancers $[12,13]$ and contributes to tumor initiation, cancer progression and clinical outcome of cancer patients $[13,14]$, which suggests that miRNAs could be potential targets for cancer therapy, and studies on miRNAs have provided a new possibility for the 
treatment of cancer.

MiRNAs can either function as oncogenes or tumor suppressors, in accordance with their expression in malignancies and the role in cellular transformation.

Overexpression of oncogenic miRNAs is to be related with transformation, metastasis, increased cell viability and proliferation in many solid malignancies. Some miRNAs have been shown to possess tumor suppressor character, as loss of function of them promotes tumourigenesis $[15,16]$. In this regard, therapeutic potentials of RNA oligonucleotides have been proposed as the most direct way for molecules to correct the abnormally expressed miRNAs, including two possible approaches of blocking oncogenic miRNAs using antimiRNA oligonucleotides or replacing tumor suppressor miRNAs using miRNA mimetics [17].

However, in contrast to some other types of cancer, such as breast cancer and colorectal cancer, little is identified about the function of miRNAs in the pathogenesis of OS. It was found that OS cell lines in general are extremely tumorigenic by evaluating the in vivo tumorigenicity, in vitro colony-forming potential, invasive/migratory capacity and proliferation ability of 22 OS cell lines. There was a strong association among motility, invasion and colony formation, especially for the exceedingly aggressive OS cell lines, such as HOS143B. Comparing the miRNA expression profiles of high (such as MG-63, HOS and OSA) and low (such as HAL, IOR/MOS, IOR/OS9, IOR/OS14 and ZK-58) clonogenic OS cell lines discovered that miRNAs were differentially expressed between the two groups. One of them was miR-155-5p, which was highly expressed in all OS cell lines that formed a high number of colonies, and less expressed or absent in OS cell lines having a low clonogenic capability [18]. Tumorigenic and nontumorigenic OS cell subpopulations also exhibit distinct miRNA expression profiles. A total of 268 miRNAs were identified significantly dysregulated in OS cell line MG-63 compared with the osteoblast cell line HOB [19].

The aim of this meta-analysis is to evaluate the potential value of miRNAs as therapeutic targets for OS based on the published literatures, and to explore the methodological quality of current studies, with the intention to guide the rigour of preclinical experimental design and the future clinical trials.

\section{RESULTS}

\section{Literature selection}

The outline of literature selection process is shown in Figure 1. Our database search retrieved 1171 publications following the search strategy described in the section of methods and 20 of the duplicated ones

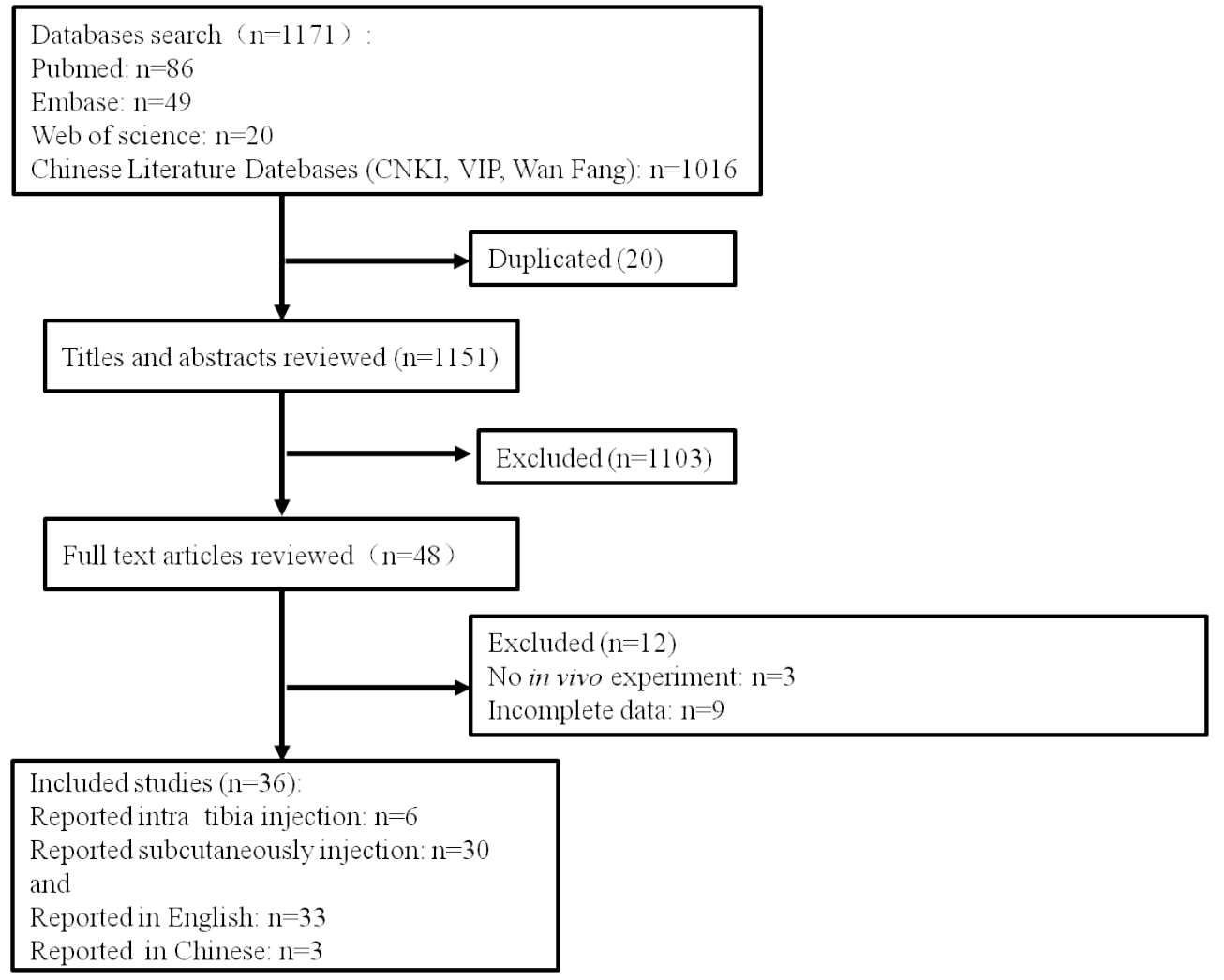

Figure 1: Schematic representation of the literature identification and selection process. 
Table 1: Description of the characteristics of studies included in the meta-analysis. $(\mathrm{NC}=$ negative control)

\begin{tabular}{|c|c|c|c|c|c|c|c|}
\hline Study & Animals & $\begin{array}{l}\text { Number } \\
\text { of } \\
\text { animals }\end{array}$ & $\begin{array}{l}\text { Osteosarcoma } \\
\text { xerograph } \\
\text { method }\end{array}$ & miRNA & Experimental groups & Control group & Outcome \\
\hline Lei Fan 2013[65] & $\begin{array}{l}16 \text { female or male } \\
\text { BALB/c nude mice }\end{array}$ & $8 / 8$ & Subcutaneous & miR-145 & MG-63+miR-145 & MG-63 & $\begin{array}{l}\text { Tumor volume } \\
\text { Tumor weight }\end{array}$ \\
\hline Jie Gao 2012[64] & $\begin{array}{l}10 \text { female BALB/c nude } \\
\text { mice ( } 4 \text { weeks) }\end{array}$ & $5 / 5$ & Intratibial & miR-195 & $\begin{array}{l}\text { F5M2+pSilencer } \\
\text { 4.1-CMV-miR-195 }\end{array}$ & $\begin{array}{l}\text { F5M2+pSilencer } \\
\text { 4.1-CMV-NC }\end{array}$ & $\begin{array}{l}\text { Tumor volume } \\
\text { Tumor weight }\end{array}$ \\
\hline Jie Jin 2013[63] & 15 SCID nude mice & $5 / 5 / 5$ & Subcutaneous & $\operatorname{miR}-218$ & $\begin{array}{l}\text { Saos-2+pcDNA3.1- } \\
\text { miR-218 }\end{array}$ & $\begin{array}{l}\text { A:Saos-2 B:Saos- } \\
\text { 2+pcDNA3.1-NC }\end{array}$ & Tumor volume \\
\hline Fang Ji 2013(a)[40] & $\begin{array}{l}8 \mathrm{BALB} / \mathrm{c} \text { nude mice (4 } \\
\text { weeks) }\end{array}$ & $4 / 4$ & Subcutaneous & miR-133a & MG-63+miR-133a & MG-63+NC & Tumor volume \\
\hline Fang Ji 2013(b)[40] & $\begin{array}{l}8 \mathrm{BALB} / \mathrm{c} \text { nude mice (4 } \\
\text { weeks) }\end{array}$ & $4 / 4$ & Subcutaneous & miR-133a & $\mathrm{U} 2 \mathrm{OS}+\mathrm{miR}-133 \mathrm{a}$ & $\mathrm{U} 2 \mathrm{OS}+\mathrm{NC}$ & Tumor volume \\
\hline $\begin{array}{l}\text { Chi Cheng } 2014 \\
{[44]}\end{array}$ & $\begin{array}{l}12 \mathrm{BALB} / \mathrm{c} \text { nude mice (4 } \\
\text { weeks) }\end{array}$ & $6 / 6$ & Subcutaneous & $\operatorname{miR}-320$ & $\mathrm{U} 2 \mathrm{OS}+\mathrm{miR}-320$ & $\mathrm{U} 2 \mathrm{OS}+\mathrm{NC}$ & $\begin{array}{l}\text { Tumor volume } \\
\text { Tumor weight }\end{array}$ \\
\hline $\begin{array}{l}\text { Guoxing } \mathrm{Xu} 2014 \\
\text { [35] }\end{array}$ & 10 & $5 / 5$ & Subcutaneous & $\begin{array}{l}\operatorname{miR}-142- \\
3 \mathrm{p}\end{array}$ & $\begin{array}{l}\text { HOS }+ \text { pcDNA3 } 3.1- \\
\text { miR-142-3p }\end{array}$ & HOS+pcDNA3.1 & $\begin{array}{l}\text { Tumor volume } \\
\text { Tumor weight }\end{array}$ \\
\hline $\begin{array}{l}\text { Hao Zhang 2010(a) } \\
{[41]}\end{array}$ & $\begin{array}{l}12 \text { female BALB/c nude } \\
\text { mice ( } 4 \text { weeks) }\end{array}$ & $6 / 6$ & Subcutaneous & $\operatorname{miR}-143$ & MG-63+miR-143 & MG-63+NC & Tumor volume \\
\hline $\begin{array}{l}\text { Hao Zhang 2010(b) } \\
{[41]}\end{array}$ & $\begin{array}{l}12 \text { female BALB/c nude } \\
\text { mice ( } 4 \text { weeks) }\end{array}$ & $6 / 6$ & Subcutaneous & miR-143 & $\mathrm{U} 2 \mathrm{OS}+\mathrm{miR}-143$ & $\mathrm{U} 2 \mathrm{OS}+\mathrm{NC}$ & Tumor volume \\
\hline $\begin{array}{l}\text { Tomohiro Fujiwara } \\
2014 \text { [43] }\end{array}$ & $\begin{array}{l}25 \text { athymic nude mice } \\
\text { (5weeks) }\end{array}$ & $5 / 5 / 5 / 5 / 5$ & Intratibial & miR-133a & $\begin{array}{l}\text { A:143B, LNA-miR- } \\
\text { 133a/Saline B:143B, } \\
\text { LNA-NC/CDDP } \\
\text { C:143B, LNA-miR- } \\
\text { 133a/CDDP Injected } \\
\text { via the tail vain }\end{array}$ & $\begin{array}{l}\text { A: 143B, Saline/ } \\
\text { Saline B:143B, } \\
\text { LNA-NC/Saline } \\
\text { Injected via the tail } \\
\text { vain }\end{array}$ & Tumor weight \\
\hline Lei Song 2013[38] & $\begin{array}{l}8 \text { female BALB/c nude } \\
\text { mice }(5-6 \text { weeks })\end{array}$ & $4 / 4$ & Subcutaneous & $\operatorname{miR}-24$ & $\begin{array}{l}\text { MG-63 +lentiviruse- } \\
\text { miR-24 }\end{array}$ & $\begin{array}{l}\text { MG-63+lentiviruse- } \\
\text { NC }\end{array}$ & Tumor volume \\
\hline $\begin{array}{l}\text { Xinyu Wu 2013(a) } \\
{[36]}\end{array}$ & $\begin{array}{l}18 \text { female BALB/c nude } \\
\text { mice (4-6weeks) }\end{array}$ & $6 / 6 / 6$ & Subcutaneous & miR-34a & $\begin{array}{l}\text { MG-63+pcDNA3.1 } \\
\text {-miR-34a }\end{array}$ & $\begin{array}{l}\text { A:MG-63 B:MG- } \\
\text { 63+pcDNA3.1 }\end{array}$ & Tumor volume \\
\hline Jin Wang 2014 [37] & $10 \mathrm{BALB} / \mathrm{c}$ nude mice & $5 / 5$ & Subcutaneous & miR-132 & $\begin{array}{l}\text { 143B+lentiviruse- } \\
\text { miR-132 }\end{array}$ & $\begin{array}{l}143 \mathrm{~B}+\text { lentiviruse- } \\
\mathrm{NC}\end{array}$ & $\begin{array}{l}\text { Tumor volume } \\
\text { Tumor weight }\end{array}$ \\
\hline $\begin{array}{l}\text { Guodong } \text { LI } 2012 \\
\text { [39] }\end{array}$ & $\begin{array}{l}18 \quad \text { nude mice } \\
(4-6 \text { weeks })\end{array}$ & $6 / 6 / 6$ & Subcutaneous & miR-223 & $\begin{array}{l}\text { MG-63, pcDNA- } \\
\text { miR-223 Intratumor } \\
\text { injection }\end{array}$ & $\begin{array}{l}\text { A:MG-63,PBS } \\
\text { B:MG-63,pcDNA3.1 } \\
\text { Intratumor injection }\end{array}$ & Tumor volume \\
\hline Lei Chen 2013 [45] & $\begin{array}{l}10 \text { male BALB/c nude } \\
\text { mice (5weeks) }\end{array}$ & $5 / 5$ & Subcutaneous & miR-16 & $\begin{array}{l}\text { U2 OS +lentiviruse- } \\
\text { miR-16 }\end{array}$ & $\begin{array}{l}\text { U2 OS+lentiviruse- } \\
\text { NC }\end{array}$ & $\begin{array}{l}\text { Tumor volume } \\
\text { Tumor weight }\end{array}$ \\
\hline $\begin{array}{l}\text { Zhengyu } \quad \mathrm{Xu} \\
2014[34]\end{array}$ & $12 \mathrm{BALB} / \mathrm{c}$ nude mice & $6 / 6$ & Subcutaneous & $\operatorname{miR}-214$ & $\begin{array}{l}\text { Saos-2 +lentiviruse- } \\
\text { miR-214 }\end{array}$ & $\begin{array}{l}\text { Saos-2+lentiviruse- } \\
\text { NC }\end{array}$ & $\begin{array}{l}\text { Tumor volume } \\
\text { Tumor weight }\end{array}$ \\
\hline $\begin{array}{l}\text { Xinyu Wu 2013(b) } \\
{[36]}\end{array}$ & $\begin{array}{l}18 \text { female BALB/c nude } \\
\text { mice (4-6weeks) }\end{array}$ & $6 / 6 / 6$ & Subcutaneous & miR-34a & $\begin{array}{l}\text { Saos-2+pcDNA3.1 } \\
\text {-miR-34a }\end{array}$ & $\begin{array}{l}\text { A:Saos-2 B:Saos- } \\
2+\text { pcDNA3.1 }\end{array}$ & Tumor volume \\
\hline Kang Yan 2012 [33] & $\begin{array}{l}12 \text { female BALB/c nude } \\
\text { mice (4weeks) }\end{array}$ & $6 / 6$ & Intratibial & $\mathrm{miR}-34 \mathrm{a}$ & $\begin{array}{l}\text { SOSP-9607+pcDNA- } \\
\text { miR-34a }\end{array}$ & $\begin{array}{l}\text { SOSP- } \\
9607+\text { pcDNA3.1 }\end{array}$ & $\begin{array}{l}\text { Tumor volume } \\
\text { Tumor weight }\end{array}$ \\
\hline $\begin{array}{l}\text { Mitsuhiko } \quad \text { Osaki } \\
2011[17]\end{array}$ & $\begin{array}{l}20 \text { male nude mice } \\
(5-6 \text { weeks })\end{array}$ & $10 / 10$ & Intratibial & miR-143 & $\begin{array}{l}143 \mathrm{~B}+\mathrm{Luc}, \mathrm{miR}-143 \\
\text { Injected via the tail } \\
\text { vain }\end{array}$ & $\begin{array}{l}143 \mathrm{~B}+\mathrm{Luc}, \mathrm{NC} \\
\begin{array}{l}\text { Injected via the tail } \\
\text { vain }\end{array}\end{array}$ & Tumor weight \\
\hline Kang Han 2014 [42] & $\begin{array}{l}30 \text { female BALB/c nude } \\
\text { mice (4weeks) }\end{array}$ & $10 / 10 / 10$ & Intratibial & miR-194 & $\begin{array}{l}\text { SOSP- } \\
\text { 9607+lentiviruse- } \\
\text { miR-194 }\end{array}$ & $\begin{array}{l}\text { A:SOSP-9607 } \\
\text { B:SOSP- } \\
\text { 9607+lentiviruse- } \\
\text { NC } \\
\end{array}$ & $\begin{array}{l}\text { Tumor volume } \\
\text { Tumor weight }\end{array}$ \\
\hline Xin Zhou 2013 [32] & $\begin{array}{l}12 \text { BALB/c nude mice } \\
\text { (5weeks) }\end{array}$ & $6 / 6$ & Subcutaneous & miR-340 & $\begin{array}{l}\text { Saos-2+lentiviruse- } \\
\text { miR-340 }\end{array}$ & $\begin{array}{l}\text { Saos-2+lentiviruse- } \\
\text { NC }\end{array}$ & Tumor weight \\
\hline $\begin{array}{l}\text { Masanori } \text { Kawano } \\
2015[56]\end{array}$ & $\begin{array}{l}21 \mathrm{BALB} / \mathrm{c} \text { nude mice } \\
\text { (6 weeks) }\end{array}$ & $7 / 7 / 7$ & Subcutaneous & miR-93 & Saos-2+miR-93 & $\begin{array}{l}\text { A:Saos-2+NC } \\
\text { B:Untreated } \\
\end{array}$ & Tumor volume \\
\hline $\begin{array}{l}\text { Yong Zhao } 2015 \\
{[47]}\end{array}$ & $\begin{array}{l}12 \text { male athymic nude } \\
\text { mice }(4-6 \text {-weeks) }\end{array}$ & $6 / 6$ & Subcutaneous & $\operatorname{miR}-34 a$ & $\begin{array}{l}143 \mathrm{~B}, \mathrm{miR}-34 \mathrm{a} \\
\text { Injected via tail vein }\end{array}$ & $\begin{array}{l}\text { Vehicle } \\
\text { Injected via tail vein }\end{array}$ & $\begin{array}{l}\text { Tumor volume } \\
\text { Tumor weight }\end{array}$ \\
\hline $\begin{array}{l}\text { K Tian } \\
2015[51]\end{array}$ & $\begin{array}{l}30 \mathrm{C} 57 \mathrm{BL} / 6 \text { mice (8 } \\
\text { weeks) }\end{array}$ & $10 / 10 / 10$ & Subcutaneous & $\operatorname{miR}-23 a$ & $\begin{array}{l}\text { HOS58+ pGL3- } \\
\text { miR23a-EGFP }\end{array}$ & $\begin{array}{l}\text { A:HOS58 } \\
\text { B: HOS58+ pGL3- } \\
\text { Ctrl-EGFP }\end{array}$ & $\begin{array}{l}\text { Tumor volume } \\
\text { Tumor weight }\end{array}$ \\
\hline
\end{tabular}




\begin{tabular}{|c|c|c|c|c|c|c|c|}
\hline $\begin{array}{l}\text { Guoqing Duan } \\
2015[60]\end{array}$ & $\begin{array}{l}14 \text { female } \mathrm{BALB} / \mathrm{c} \text { nude } \\
\text { mice }(6 \text { weeks })\end{array}$ & $7 / 7$ & Subcutaneous & $\operatorname{miR}-26 b$ & $\mathrm{U} 2 \mathrm{OS}+$ pcDNA3.1-miR-26b & $\begin{array}{l}\mathrm{U} 2 \mathrm{OS}+\mathrm{pcDNA} 3.1- \\
\text { anti-miR-26b }\end{array}$ & Tumor volume \\
\hline $\begin{array}{l}\text { Jiahui Zhou } \\
\text { (a)2015 [46] }\end{array}$ & $\begin{array}{l}18 \quad \mathrm{BALB} / \mathrm{c} \quad \text { nude } \\
\operatorname{mice}(20 \mathrm{~g})\end{array}$ & $9 / 9$ & Subcutaneous & miR-143 & $\begin{array}{l}\text { Saos-2, } \\
\text { intratumorally }\end{array}$ & $\begin{array}{l}\text { Saos-2, ADNC } \\
\text { intratumorally }\end{array}$ & Tumor weight \\
\hline $\begin{array}{l}\text { Jiahui Zhou } \\
\text { (b) } 2015[46]\end{array}$ & $\begin{array}{l}18 \quad \mathrm{BALB} / \mathrm{c} \quad \text { nude } \\
\operatorname{mice}(20 \mathrm{~g})\end{array}$ & $9 / 9$ & Subcutaneous & $\operatorname{miR}-143$ & $\begin{array}{l}\text { U2OS, } \\
\text { intratumorally }\end{array}$ & $\begin{array}{l}\text { U2OS, ADNC } \\
\text { intratumorally }\end{array}$ & Tumor weight \\
\hline $\begin{array}{l}\text { Wei Wang } \\
2015[61]\end{array}$ & $\begin{array}{l}12 \mathrm{BALB} / \mathrm{c} \text { nude mice (4 } \\
\text { weeks) }\end{array}$ & $6 / 6$ & Subcutaneous & miR-144 & 143B+ lentiviruse-miR-144 & $\begin{array}{l}143 \mathrm{~B}+\text { lentiviruse- } \\
\mathrm{NC}\end{array}$ & $\begin{array}{l}\text { Tumor volume } \\
\text { Tumor weight }\end{array}$ \\
\hline $\begin{array}{l}\text { Xiaoji Luo } \\
2014[54]\end{array}$ & $\begin{array}{l}10 \text { male BALB/c nude } \\
\text { mice ( } 4 \text { weeks) }\end{array}$ & $5 / 5$ & Subcutaneous & miR-212 & MG-63+ miR-212 & MG-63+NC & $\begin{array}{l}\text { Tumor volume } \\
\text { Tumor weight }\end{array}$ \\
\hline $\begin{array}{l}\text { Xuming Wang } \\
2014[50]\end{array}$ & $\begin{array}{l}8 \mathrm{BALB} / \mathrm{c} \text { nude mice (4-6 } \\
\text { weeks) }\end{array}$ & $4 / 4$ & Subcutaneous & $\operatorname{miR}-214$ & Saos-2+pcDNA3.1-miR-214 & Saos-2+pcDNA3.1 & $\begin{array}{l}\text { Tumor volume } \\
\text { Tumor weight }\end{array}$ \\
\hline $\begin{array}{l}\text { Wei Liu } 2015 \\
{[55]}\end{array}$ & $\begin{array}{l}10 \mathrm{BALB} / \mathrm{c} \text { nude mice }(6 \\
\text { weeks) }\end{array}$ & $5 / 5$ & Subcutaneous & $\begin{array}{l}\operatorname{miR}-49 \\
0-3 p\end{array}$ & Saos-2+ miR-49 0-3p & Saos- $2+\mathrm{NC}$ & $\begin{array}{l}\text { Tumor volume } \\
\text { Tumor weight }\end{array}$ \\
\hline $\begin{array}{l}\text { Liang Ge } \\
2016[59]\end{array}$ & $\begin{array}{l}20 \text { male BALB/c mice(5-6 } \\
\text { weeks) }\end{array}$ & $10 / 10$ & Subcutaneous & $\operatorname{miR}-497$ & MG-63+ miR-497 & MG-63+NC & $\begin{array}{l}\text { Tumor volume } \\
\text { Tumor weight }\end{array}$ \\
\hline $\begin{array}{l}\text { Xiuhui Wang } \\
2014[49]\end{array}$ & $\begin{array}{l}12 \text { male } \mathrm{BALB} / \mathrm{c} \text { nude } \\
\text { mice ( } 4 \text { weeks) }\end{array}$ & $6 / 6$ & Subcutaneous & $\operatorname{miR}-25$ & Saos-2+ miR-25 & Saos-2+NC & Tumor weight \\
\hline $\begin{array}{ll}\mathrm{Yu} & \mathrm{He} \\
2014[58] & \end{array}$ & $\begin{array}{l}16 \text { male BALB/c nude } \\
\text { mice ( } 5 \text { weeks) }\end{array}$ & $8 / 8$ & Subcutaneous & $\operatorname{miR}-23 a$ & $\begin{array}{l}\text { MG-63, } \\
\text { intratumorally }\end{array}$ & MG-63, NC & $\begin{array}{l}\text { Tumor volume } \\
\text { Tumor weight }\end{array}$ \\
\hline $\begin{array}{l}\text { Xiaohui } \\
2015[52]\end{array}$ & $\begin{array}{l}12 \text { male } \mathrm{BALB} / \mathrm{c} \text { nude } \\
\text { mice }\end{array}$ & $6 / 6$ & Subcutaneous & miR-155 & $\begin{array}{l}\text { U2OS, anti-miR-155 } \\
\text { intratumorally }\end{array}$ & $\begin{array}{l}\mathrm{U} 2 \mathrm{OS}, \quad \text { anti-NC } \\
\text { intratumorally }\end{array}$ & $\begin{array}{l}\text { Tumor volume } \\
\text { Tumor weight }\end{array}$ \\
\hline $\begin{array}{l}\text { Zhengwen Sun } \\
2014[25]\end{array}$ & $\begin{array}{l}10 \text { male } \mathrm{BALB} / \mathrm{c} \text { nude } \\
\text { mice ( } 4 \text { weeks) }\end{array}$ & $5 / 5$ & Subcutaneous & miR-202 & HOS+ lentiviruse-miR-202 & $\begin{array}{l}\text { HOS+ lentiviruse- } \\
\mathrm{NC}\end{array}$ & $\begin{array}{l}\text { Tumor volume } \\
\text { Tumor weight }\end{array}$ \\
\hline $\begin{array}{ll}\text { Meng } & \mathrm{Xu} \\
2014[48] & \end{array}$ & $\begin{array}{l}16 \text { female athymic nude } \\
\text { mice }(6 \text { weeks })\end{array}$ & $8 / 8$ & Subcutaneous & $\operatorname{miR}-382$ & $\begin{array}{l}\text { CD133high OS primary } \\
\text { tumor cell }+ \text { miR-382 }\end{array}$ & $\begin{array}{lr}\text { CD133high } & \text { OS } \\
\text { primary } & \text { tumor } \\
\text { cell+NC } & \end{array}$ & Tumor volume \\
\hline $\begin{array}{l}\text { Baoyong Sun } \\
2015[53]\end{array}$ & $\begin{array}{l}16 \quad \text { female } \text { BALB/c } \\
\text { athymic nude mice }(3-4 \\
\text { weeks) }\end{array}$ & $8 / 8$ & Subcutaneous & $\operatorname{miR}-217$ & $\begin{array}{l}\text { MG-63+ lentiviruse -miR- } \\
217\end{array}$ & $\begin{array}{l}\text { MG-63+ lentiviruse- } \\
\text { NC }\end{array}$ & $\begin{array}{l}\text { Tumor volume } \\
\text { Tumor weight }\end{array}$ \\
\hline $\begin{array}{l}\text { Tatsuya } \\
\text { Iwasaki } \\
2015[57]\end{array}$ & 21 nude mice & 7/7/7 & Subcutaneous & miR-let-7a & MG-63+ miR-let-7a & $\begin{array}{l}\text { A: MG-63 } \\
\text { B: MG-63+NC }\end{array}$ & Tumor volume \\
\hline $\begin{array}{ll}\text { Kang } & \text { Han } \\
2015[62] & \end{array}$ & $\begin{array}{l}20 \text { female } \mathrm{BALB} / \mathrm{c} \text { nude } \\
\text { mice }(4 \text { weeks })\end{array}$ & $10 / 10$ & Intratibial & miR-195 & $\begin{array}{l}\text { SOSP-9607+ lentiviruse } \\
\text {-miR-195 }\end{array}$ & $\begin{array}{l}\text { SOSP-9607+ } \\
\text { lentiviruse -NC }\end{array}$ & $\begin{array}{l}\text { Tumor volume } \\
\text { Tumor weight }\end{array}$ \\
\hline
\end{tabular}

were excluded. After reading the titles and abstracts, 1103 publications were excluded. By a full text review of the 48 publications, 12 studies were further excluded due to they had no in vivo experiments [20-22] $(n=3)$ or exhibited incomplete data $[23-31](n=9)$. Thirty six of the publications met the criteria were included in the final meta-analysis. Thirty three of the publications were reported in English [17, 25, 32-62], and 3 of them were reported in Chinese [63-65].

\section{Study characteristics}

Among all the 36 included studies, 34 of them used nude mice, while the strain of mice used in 2 studies was not clear. Ten studies used female mice, 9 studies used males, 1 study used female or male mice, and the gender of mice in 16 studies was not presented in the literatures.

Median sample size of mice for the 36 included studies was 16 (range from 8 to 30). The main composition of background diet used in the included studies was not reported. OS xenograft models of the mice used in 30 studies were established by subcutaneous injection, and in 6 studies were established by intratibial injection.

MiRNAs were transfected into human OS cells before inoculating mice ( 29 of 36 included studies) [ 25 , $32-38,40-42,44,45,48-50,53-65]$, injected into the tumor ( 4 of 36 included studies) [39, 46, 52, 58], systemic administrated by tail vain injection( 3 of 36 included studies) [17, 43, 47]. The included studies reported the outcomes of tumor weight, tumor volume, or both of them (Table 1).

\section{Quality assessments of the included experiments}

The quality assessment of each included publication in this meta-analysis is shown in Table 2. No studies 
Table 2: Quality assessment of the included experiments

\begin{tabular}{|c|c|c|c|c|c|c|c|}
\hline Study & $\begin{array}{l}\text { Sample- } \\
\text { size } \\
\text { calculation }\end{array}$ & $\begin{array}{l}\text { Inclusion } \\
\text { and } \\
\text { exclusion } \\
\text { criteria }\end{array}$ & Randomization & $\begin{array}{l}\text { Allocation } \\
\text { concealment }\end{array}$ & $\begin{array}{l}\text { Reporting } \\
\text { of animals } \\
\text { excluded } \\
\text { from } \\
\text { analysis }\end{array}$ & $\begin{array}{l}\text { Blinded } \\
\text { assessment } \\
\text { of outcome }\end{array}$ & $\begin{array}{l}\text { Reporting } \\
\text { potential } \\
\text { conflicts } \\
\text { of interest } \\
\text { and study } \\
\text { funding }\end{array}$ \\
\hline Lei Fan 2013 [65] & Unclear & Unclear & Yes & Unclear & Unclear & Unclear & Unclear \\
\hline Jie Gao 2012 [64] & Unclear & Unclear & Unclear & Unclear & Unclear & Unclear & Yes \\
\hline Jie Jin 2013 [63] & Unclear & Unclear & Unclear & Unclear & Unclear & Unclear & Unclear \\
\hline Fang Ji 2013[40] & Unclear & Unclear & Unclear & Unclear & Unclear & Unclear & Yes \\
\hline Chi Cheng 2014 [44] & Unclear & Unclear & Unclear & Unclear & Unclear & Unclear & Yes \\
\hline \begin{tabular}{ll|} 
Tomohiro & Fujiwara \\
$2014[43]$ & \\
\end{tabular} & Unclear & Unclear & Unclear & Unclear & Unclear & Unclear & Yes \\
\hline Hao Zhang 2010 [41] & Unclear & Unclear & Unclear & Unclear & Unclear & Unclear & Unclear \\
\hline Lei Song 2013 [38] & Unclear & Unclear & Unclear & Unclear & Unclear & Unclear & Unclear \\
\hline Xinyu Wu 2013 [36] & Unclear & Unclear & Unclear & Unclear & Unclear & Unclear & Yes \\
\hline Kang Yan 2012[33] & Unclear & Unclear & Unclear & Unclear & Unclear & Unclear & Yes \\
\hline $\begin{array}{|ll|}\begin{array}{l}\text { Mitsuhiko } \\
2011[17]\end{array} & \text { Osaki } \\
\end{array}$ & Unclear & Unclear & Unclear & Unclear & Unclear & Unclear & Unclear \\
\hline Kang Han 2014 [42] & Unclear & Unclear & Unclear & Unclear & Unclear & Unclear & Unclear \\
\hline Xin Zhou 2013 [32] & Unclear & Unclear & Unclear & Unclear & Unclear & Unclear & Unclear \\
\hline Zhengyu Xu 2014[34] & Unclear & Unclear & Unclear & Unclear & Unclear & Unclear & Unclear \\
\hline Lei Chen 2013 [45] & Unclear & Unclear & Unclear & Unclear & Unclear & Unclear & Unclear \\
\hline Jin Wang 2014 [37] & Unclear & Unclear & Unclear & Unclear & Unclear & Unclear & Yes \\
\hline Guoxing Xu 2014 [35] & Unclear & Unclear & Unclear & Unclear & Unclear & Unclear & Unclear \\
\hline Guodong LI 2013 [39] & Unclear & Yes & Yes & Unclear & Unclear & Unclear & Yes \\
\hline $\begin{array}{ll}\text { Masanori } & \text { Kawano } \\
2015[56] & \\
\end{array}$ & Unclear & Unclear & Unclear & Unclear & Unclear & Unclear & Yes \\
\hline Yong Zhao 2015[47] & Unclear & Unclear & Yes & Unclear & Unclear & Unclear & Yes \\
\hline K Tian 2015[51] & Unclear & Unclear & Unclear & Unclear & Unclear & Unclear & Unclear \\
\hline \begin{tabular}{ll|} 
Guoqing & Duan \\
$2015[60]$ & \\
\end{tabular} & Unclear & Unclear & Unclear & Unclear & Unclear & Unclear & Yes \\
\hline Jiahui Zhou 2015[46] & Unclear & Unclear & Yes & Unclear & Unclear & Unclear & Yes \\
\hline Wei Wang 2015[61] & Unclear & Unclear & Unclear & Unclear & Unclear & Unclear & Yes \\
\hline Xiaoji Luo 2014[54] & Unclear & Unclear & Unclear & Unclear & Unclear & Unclear & Yes \\
\hline $\begin{array}{ll}\text { Xuming } & \text { Wang } \\
2014[50] & \\
\end{array}$ & Unclear & Unclear & Unclear & Unclear & Unclear & Unclear & Yes \\
\hline Wei Liu 2015[55] & Unclear & Unclear & Yes & Unclear & Unclear & Unclear & Yes \\
\hline Liang Ge 2016[59] & Unclear & Unclear & Unclear & Unclear & Unclear & Unclear & Unclear \\
\hline Xiuhui Wang 2014[49] & Unclear & Unclear & Unclear & Unclear & Unclear & Unclear & Unclear \\
\hline Yu He 2014[58] & Unclear & Unclear & Yes & Unclear & Unclear & Unclear & Yes \\
\hline Xiaohui Sun 2015[52] & Unclear & Unclear & Unclear & Unclear & Unclear & Unclear & Yes \\
\hline $\begin{array}{ll}\text { Zhengwen } & \text { Sun } \\
2014[25] & \\
\end{array}$ & Unclear & Unclear & Unclear & Unclear & Unclear & Unclear & Yes \\
\hline Meng Xu 2014[48] & Unclear & Unclear & Unclear & Unclear & Unclear & Unclear & Yes \\
\hline Baoyong Sun 2015[53] & Unclear & Unclear & Unclear & Unclear & Unclear & Yes & Yes \\
\hline $\begin{array}{ll}\text { Tatsuya } & \text { Iwasaki } \\
2015[57] & \\
\end{array}$ & Unclear & Unclear & Unclear & Unclear & Unclear & Unclear & Yes \\
\hline Kang Han 2015[62] & Unclear & Unclear & Unclear & Unclear & Unclear & Unclear & Yes \\
\hline
\end{tabular}


included here described allocation concealment and sample-size calculation, reported animals excluded from analysis or blinded assessment of outcome. One study reported inclusion and exclusion criteria [39]. Six studies reported randomization [39, 46, 47, 55, 58, 65], whereas 23 studies reported potential conflicts of interest and study funding $[25,33,36,37,39,40,43,44,46-48,50,52-58$, 60-62, 64]. Only one study reported blinded assessment of outcome [53]. Therefore, the methodological quality of studies included here was not satisfied.

\section{Inhibitory effects on the tumor growth (tumor weight/ tumor volume) of osteosarcoma xenograft models by correction of the abnormally expressed miRNAs}

Due to the data used for this systematic review and meta-analysis were experiment-levels, different major outcome measures (tumor weight or tumor volume); different types(miR-195, miR-143, miR-34a, miR-214, miR-23a, miR-133a, and so on) or functions(oncogenes or tumor suppressors) of miRNAs; different miRNA intervention methods(directly transfected into OS cells, transfected into OS cells with plasmid vectors, infected into OS cells by lentivirus vectors, systematic administration or injected into tumor directly); different OS cells(MG-63, U2 OS, Saos-2,143B or SOSP-9607) and inoculation sites for producing xenograft models (intratibial inoculation or subcutaneous inoculation) were used in the included studies, these factors all could potentially produce a high heterogeneity. However, if all the baseline characteristics among groups were balanced, the data could not be evaluated. Therefore, stratifications were performed based on these factors to minimize the heterogeneity. Meanwhile, random-effects models were used for the analyses.

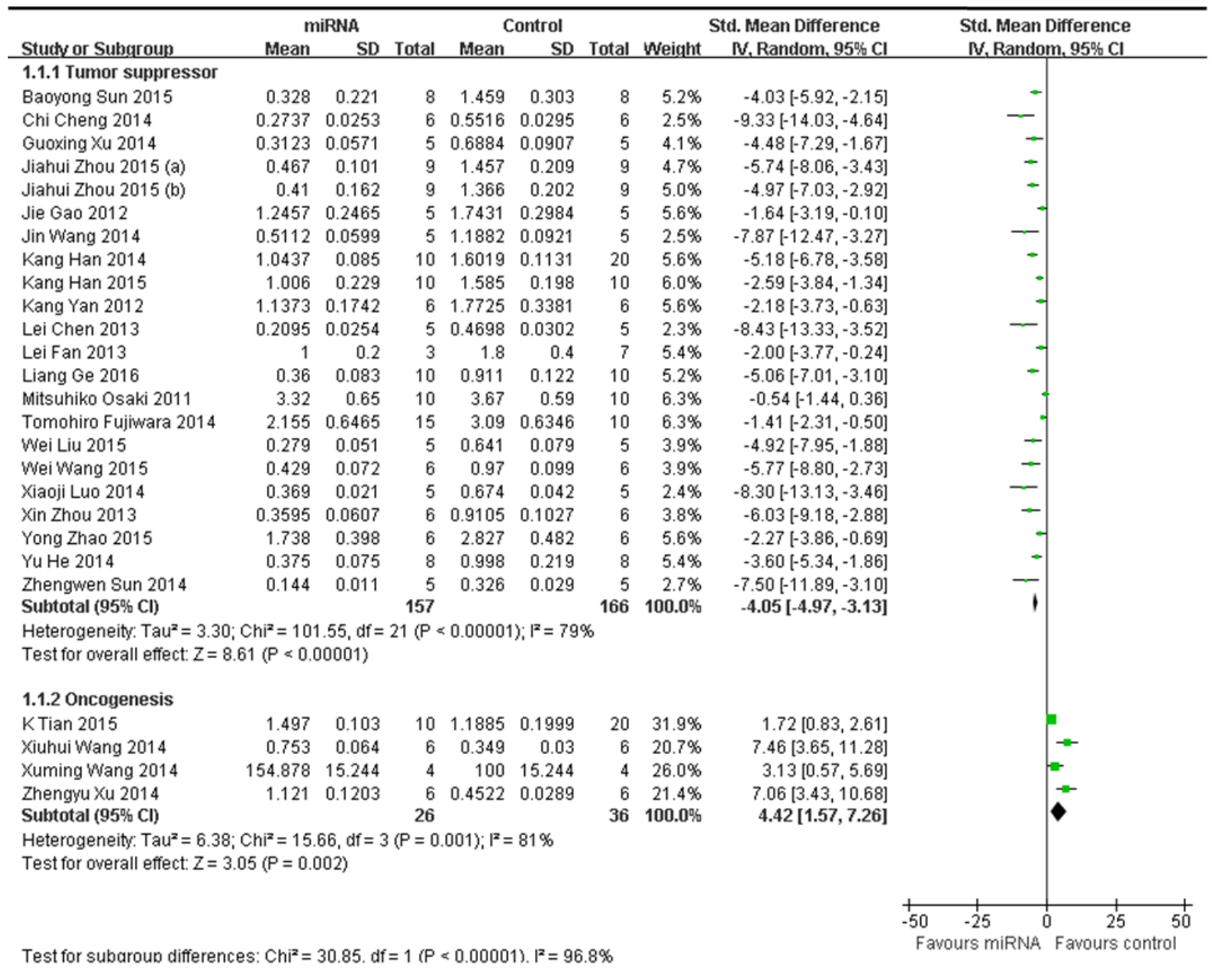

Figure 2: Meta-analysis of studies evaluating the inhibitory effects on tumor weight after the aberrantly expressed miRNAs were corrected, when all included studies used tumor weight as the major outcome measure were stratified by the function of miRNAs in the pathogenesis of osteosarcoma. SD, standard deviation; CI, confidence interval. 
When all the included studies used tumor weight as the major outcome measure were stratified by whether the aberrantly expressed miRNAs function as oncogenes or tumor suppressors in the pathogenesis of osteosarcoma

Since the mechanisms of oncogenes or tumor suppressors in the pathogenesis of OS are different, we conducted the delaminating analysis.

Twenty-one of the 25 studies reported that miRNAs function as the tumor suppressors and thus the data were combined for a meta-analysis $[17,25,32,33,35,37,42$ $47,53-55,58,59,61,62,64,65]$. A total of 157 mice in the intervention arm and 166 in the control arm were included. The results suggested that restoring the decreased tumor suppressor miRNAs was able to restrain the progression of OS in vivo when a random-effects model was used. And the pooled $\mathrm{MD}=[-4.05] ; 95 \%$ confidence interval $[\mathrm{CI}]$ : [-4.97]- [-3.13]; $p<0.00001$ (Figure 2 upper part).

Four of the 25 studies reported that miRNAs functions as onco-miRNAs in OS [34, 49-51]. A total of 26 mice in the intervention arm and 36 in the control arm were included. The results suggested that decreasing the tumor onco-miRNAs was also able to restrain the OS progression in vivo when a random-effects model was used. And the pooled MD $=[4.42] ; 95 \%$ confidence interval [CI]: [1.57]- [7.26]; $p=0.001$; Figure 2, lower part.

When above included studies that reported miRNAs as tumor suppressors or oncogenes were further stratified respectively by the following factors

\section{The miRNA delivery method}

There were 21 studies which reported that tumor weight as the major outcome measure and miRNAs as tumor suppressors. MiRNAs were directly transfected into the OS cells in 5 studies, and thus the data were combined for a meta-analysis $[44,54,55,59,65]$. There were 29 mice in the intervention arm and 33 mice in the control arm. The tumor weight showed a significant statistical difference when the decreased tumor suppressor miRNAs were corrected (pooled MD $=[-5.28] ; 95 \%$ confidence interval [CI]: [-7.69]- [-2.87]; $p=0.006$; Figure 3A, part 1) in a random-effects model. MiRNAs with plasmid vectors were transfected into the OS cells in 3 studies, and were combined for a meta-analysis. There were 16 mice in both the intervention and control arms. Tumor weight was also significantly inhibited after the correction of the decreased tumor suppressor miRNAs (pooled MD $=[-2.37] ; 95 \%$ confidence interval [CI]: [-3.68]- [1.06]; $p=0.22$; Figure $3 \mathrm{~A}$, part 2) in a random-effects model $[33,35,64]$. MiRNAs were infected into the OS cells by lentivirus vectors in 8 studies, and were combined for a meta-analysis. There were 55 mice in the intervention arm and 65 in the control arm. The tumor weight significantly decreased when the decreased tumor suppressor miRNAs were corrected (pooled MD $=[-5.17] ; 95 \%$ confidence interval [CI]: [-6.60]- [-3.74]; $p=0.01$; Figure 3A, part 3 )in a random-effects model $[25,32,37,42,45,53,61$, 62]. MiRNAs were delivered by systematic administration after inoculation with OS cells in other 3 studies [17, 43, 47]. There were 31 mice in the intervention arm and 26 mice in the control arm. Tumor weight also showed a statistically significant decrease after the aberrantly expressed miRNAs were corrected (pooled $\mathrm{MD}=[-1.25]$; 95\% confidence interval [CI]: [-2.13]- [-0.37]; $p=0.13$; Figure 3A, part 4) in a random-effects model. MiRNAs were injected into tumor directly in 2 studies, and were combined for a meta-analysis. There were 26 mice in both of the intervention and control arms. The tumor weight significantly decreased when the aberrantly expressed miRNAs were corrected (pooled MD $=[-4.59] ; 95 \%$ confidence interval $[\mathrm{CI}]$ : [-5.84]- $[-3.34] ; p=0.31$; Figure $3 \mathrm{~A}$, part 5)in a random-effects model $[46,58]$.

There were 4 studies which reported that tumor weight as the major outcome measure and miRNAs as oncogenes. MiRNAs were transfected into OS cells with plasmid vectors in 2 studies, and the data were combined for a meta-analysis. There were 14 mice in the intervention arm and 24 in the control arm. Tumor weight was also significantly inhibited after correction of the up-regulated oncogene miRNAs (pooled MD $=[1.89] ; 95 \%$ confidence interval [CI]: [0.98]- [2.81]; $p=0.31$; Figure $3 \mathrm{~B}$ ) in a random-effects model $[50,51]$.

Only 1 study respectively reported that miRNA was either directly transfected into the OS cells or infected into the OS cells by lentivirus vectors, therefore the data could not be pooled. One of the 2 studies reported that miR-25 was transfected into OS cells directly [49]. This study confirmed that miR-25 was frequently over-expressed in OS, and up-regulation of miR-25 promoted cell proliferation in vitro and tumor growth in a xenograftmouse model. The other study reported that miR-214 was infected into OS cells by lentivirus vectors [34]. This study showed that miR-214 was frequently up-regulated in OS specimens than noncancerous, and over-expression of miR-214 could promote OS cell proliferation, invasion and tumor growth in nude mice. The weight of miR-214-overexpressing tumor was $>$ 2 -fold higher than that of the controls.

As we could see in Figure 3A, the overall effect on reducing the tumor weight via miRNAs being infected into OS cells with lentivirus vectors or transfected into OS cells directly were the best and comparable, then direct injecting miRNAs into tumors, and followed by being transfected into OS cells with plasmid vectors or systematic administration of miRNAs.

The names of miRNAs

In order to find out if different miRNA has different influence on OS growth, data of same miRNA from more than 2 studies (if have), which reported that tumor weight was the major outcome measure, were combined 


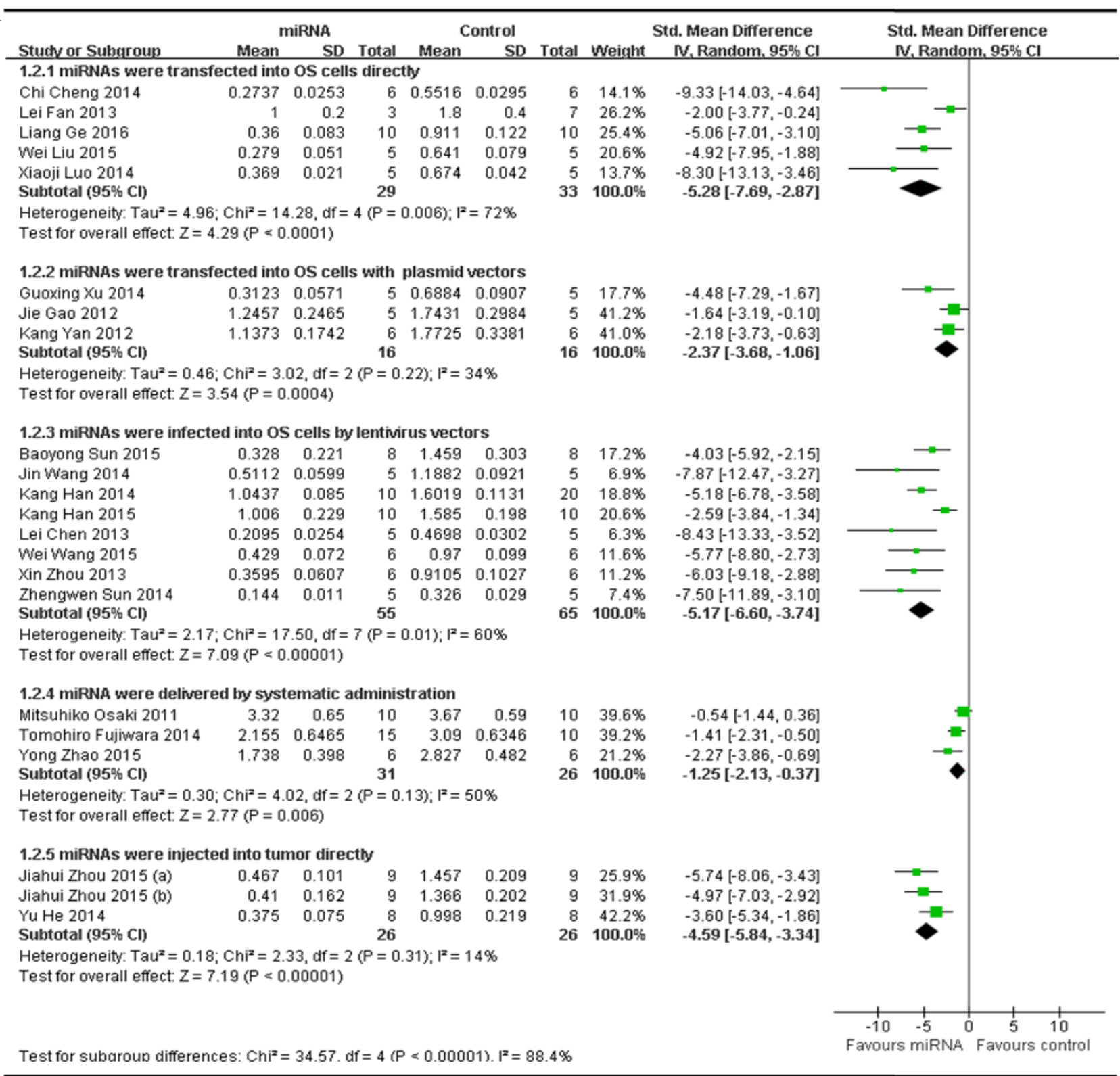

3B

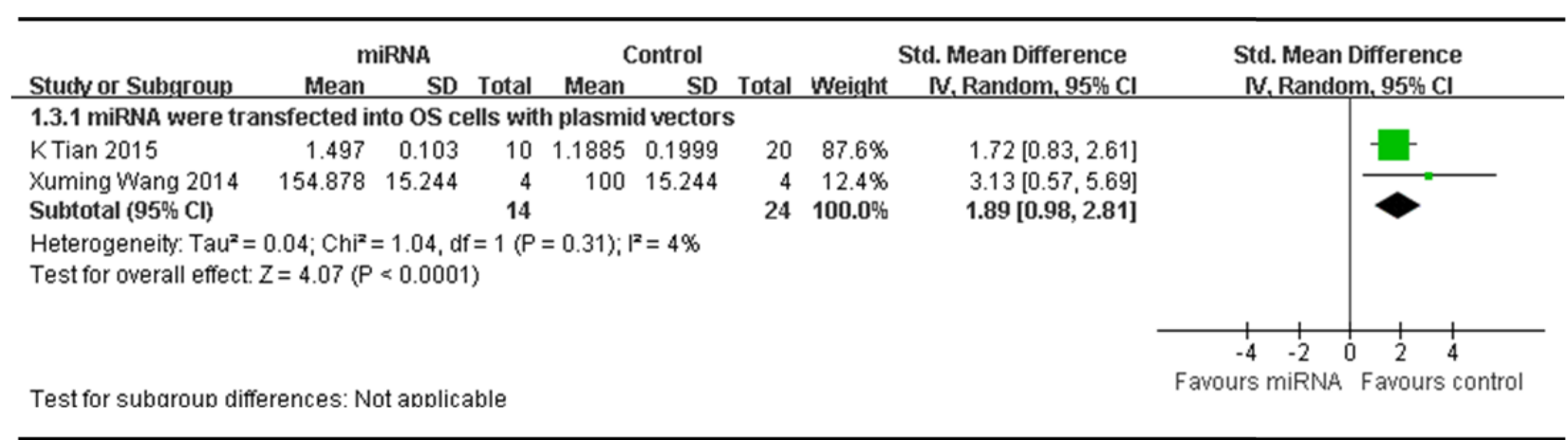

Figure 3: Meta-analysis of included studies evaluating the inhibitory effects on tumor weight after the aberrantly expressed miRNAs were corrected, when studies, reported miRNAs as tumor suppressors $\mathbf{A}$. or oncogenes $\mathbf{B}$. and used tumor weight as the major outcome measure, were stratified respectively by the miRNA delivery method. SD, standard deviation; CI, confidence interval. 
together for a meta-analysis. This resulted 4 different miRNAs were anylyzed, including 3 tumor suppressor miRNAs(miR-195, miR-143 and miR-34a) and 1 oncogene(miR-214). As shown in Figure 4, part 1, there were 15 mice in both the interventionand the control arms. Tumor weight significantly decreased when the expression of down-regulated miR-195 was recovered (pooled MD = [ -2.21]; 95\% confidence interval [CI]: [-3.19]- [-1.24]; $p$ $=0.35 ;)[62,64]$; there were 28 mice in the intervention arm and 28 in the control arm. Tumor weight significantly decreased when the expression of down-regulated miR143 was recovered (pooled $\mathrm{MD}=[-3.64]$; 95\% confidence interval [CI]: [-7.35]- [0.06]; $p<0.00001$; Figure 4, part 2) $[17,46]$; there were 12 mice in the intervention arm and 12 in the control arm. Tumor weight significantly decreased when the expression of down-regulated miR$34 \mathrm{a}$ was rescued (pooled $\mathrm{MD}=[-2.23]$; 95\% confidence interval [CI]: [-3.34]- [-1.12]; $p=0.93$; Figure 4, part 3) $[33,47]$; there were 10 mice in the intervention arm and 10 in the control arm. Tumor weight significantly decreased when the expression of up-regulated miR-214 was downregulated (pooled $\mathrm{MD}=[4.88]$; 95\% confidence interval
[CI]: [1.05]- [8.70]; $p=0.08$; Figure 4, part 4) $[34,50]$.

As we could see in Figure 4A, the effect on inhibiting tumor weight was most significant when the aberrantly expressed oncogene miR-214 was corrected, and followed by rescuing miR-143, then miR-195 or miR34a. The efficacy due to up-regulating miR-195 or miR34a was comparable.

Inoculation sites of osteosarcoma cells

There were 21 studies which reported that tumor weight as the major outcome measure and miRNAs as tumor suppressors.

Fifteen of them applied OS xenograft models produced by subcutaneous inoculation of OS cells [25, $32,35,37,44-47,53-55,58,59,61,65]$. These 15 studies were combined together for the meta-analysis, and there were 101 mice in the intervention arm and 105 in the control arm. Given that the heterogeneity was high among the studies, a random-effects model was selected, and the tumor weight considerably decreased when the decreased tumor suppressor miRNAs were corrected (pooled MD = [-4.89]; 95\% confidence interval [CI]: [-5.86]- [-3.93]; $p$ $=0.006$; Figure 5A, upper part).

\begin{tabular}{|c|c|c|c|c|c|c|c|c|c|}
\hline \multirow[b]{2}{*}{ Stucty or Subgroup } & \multicolumn{2}{|c|}{ miRNA } & \multicolumn{3}{|c|}{ Control } & \multirow[b]{2}{*}{ Total } & \multicolumn{2}{|r|}{ Std. Mean Difference } & \multirow{2}{*}{$\begin{array}{l}\text { Std. Mean Difference } \\
\text { N, Random, 95\% Cl }\end{array}$} \\
\hline & Mean & SD & Total & Mean & SD & & Weight & N, Random, $95 \% \mathrm{Cl}$ & \\
\hline \multicolumn{10}{|l|}{ 1.4.1 miR-195 } \\
\hline Jie Gao 2012 & 1.2457 & 0.2465 & 5 & 1.7431 & 0.2984 & 5 & $39.7 \%$ & $-1.64[-3.19,-0.10]$ & $=$ \\
\hline Kang Han 2015 & 1.006 & 0.229 & 10 & 1.585 & 0.198 & 10 & $60.3 \%$ & $-2.59[-3.84,-1.34]$ & \\
\hline Subtotal $(95 \% \mathrm{Cl})$ & & & 15 & & & 15 & $100.0 \%$ & $-2.21[-3.19,-1.24]$ & \\
\hline \multicolumn{10}{|c|}{$\begin{array}{l}\text { Heterogeneity: } \operatorname{Tau}^{2}=0.00 ; \mathrm{Chi}^{2}=0.87, \mathrm{df}=1(\mathrm{P}=0.35) ; \mathrm{I}^{2}=0 \% \\
\text { Test for overall effect: } Z=4.46(P<0.00001)\end{array}$} \\
\hline \multicolumn{10}{|l|}{ 1.4.2 miR-143 } \\
\hline Jiahui Zhou 2015 (a) & 0.467 & 0.101 & 9 & 1.457 & 0.209 & 9 & $31.8 \%$ & $-5.74[-8.06,-3.43]$ & $\rightarrow-$ \\
\hline Jiahui Zhou 2015 (b) & 0.41 & 0.162 & 9 & 1.366 & 0.202 & 9 & $32.7 \%$ & $-4.97[-7.03,-2.92]$ & $\rightarrow-$ \\
\hline Mitsuhiko Osaki 2011 & 3.32 & 0.65 & 10 & 3.67 & 0.59 & 10 & $35.6 \%$ & $-0.54[-1.44,0.36]$ & \\
\hline Subtotal $(95 \% \mathrm{Cl})$ & & & 28 & & & 28 & $100.0 \%$ & $-3.64[-7.35,0.06]$ & \\
\hline \multicolumn{10}{|c|}{$\begin{array}{l}\text { Heterogeneity: } \text { Tau }^{2}=9.84 ; \mathrm{Ch}^{2}=27.86, \mathrm{df}=2(P<0.00001) ; \mathrm{I}^{2}=93 \% \\
\text { Test for overall effect: } Z=1.93(P=0.05)\end{array}$} \\
\hline \multicolumn{10}{|l|}{ 1.4.3 miR-34a } \\
\hline Kang Yan 2012 & 1.1373 & 0.1742 & 6 & 1.7725 & 0.3381 & 6 & $51.0 \%$ & $-2.18[-3.73,-0.63]$ & - \\
\hline Yong Zhao 2015 & 1.738 & 0.398 & 6 & 2.827 & 0.482 & 6 & $49.0 \%$ & $-2.27[-3.86,-0.69]$ & - \\
\hline Subtotal $(95 \% \mathrm{Cl})$ & & & 12 & & & 12 & $100.0 \%$ & $-2.23[-3.34,-1.12]$ & \\
\hline \multicolumn{10}{|c|}{$\begin{array}{l}\text { Heterogeneity: } \mathrm{Tau}^{2}=0.00 ; \mathrm{Chi}^{2}=0.01, \mathrm{df}=1(P=0.93) ; I^{2}=0 \% \\
\text { Test for overall effect: } Z=3.93(P<0.0001)\end{array}$} \\
\hline \multicolumn{10}{|l|}{ 1.4.4 miR-214 } \\
\hline Xuming Wang 2014 & 154.878 & 15.244 & 4 & 100 & 15.244 & 4 & $55.6 \%$ & $3.13[0.57,5.69]$ & \\
\hline Zhengyu Xu 2014 & 1.121 & 0.1203 & 6 & 0.4522 & 0.0289 & 6 & $44.4 \%$ & $7.06[3.43,10.68]$ & \\
\hline Subtotal $(95 \% \mathrm{Cl})$ & & & 10 & & & 10 & $100.0 \%$ & $4.88[1.05,8.70]$ & \\
\hline \multicolumn{10}{|c|}{$\begin{array}{l}\text { Heterogeneity: } \operatorname{Tau}^{2}=5.14 ; \mathrm{Chi}^{2}=3.01, \mathrm{df}=1(P=0.08) ; I^{2}=67 \% \\
\text { Test for overall effect: } Z=2.50(P=0.01)\end{array}$} \\
\hline Test for subaroun diffe & Ices: Chi & $z=13.5$ & $f=3 r$ & $(P=0.00$ & 14). $\left.\right|^{2}=7$ & $.8 \%$ & & & $\begin{array}{ccccc}-10 & -5 & 0 & 5 & 10 \\
\text { Favours miRNA } & \text { Favours control }\end{array}$ \\
\hline
\end{tabular}

Figure 4: Meta-analysis of included studies evaluating the inhibitory effects on tumor weight after the aberrantly expressed miRNAs were corrected, when all included studies used tumor weight as the major outcome measure were stratified by the names of miRNAs. SD, standard deviation; CI, confidence interval. 
OS xenograft models induced by intratibial injection of OS cells were used in other 6 studies [17, 33, 42, 43, $62,64]$. Fifty-six mice in the intervention arm and 61 mice in the control arm were included. A random-effects model was used also due to the high heterogeneity among the included studies, and the tumor weight significantly decreased after the decreased tumor suppressor miRNAs were corrected (pooled MD $=[-2.17] ; 95 \%$ confidence interval [CI]: [-3.34]- [-1.00]; $p<0.0001$; Figure 5A, lower part).

As we could see in Figure 5A, the overall effects on reducing the tumor weight were more significant when

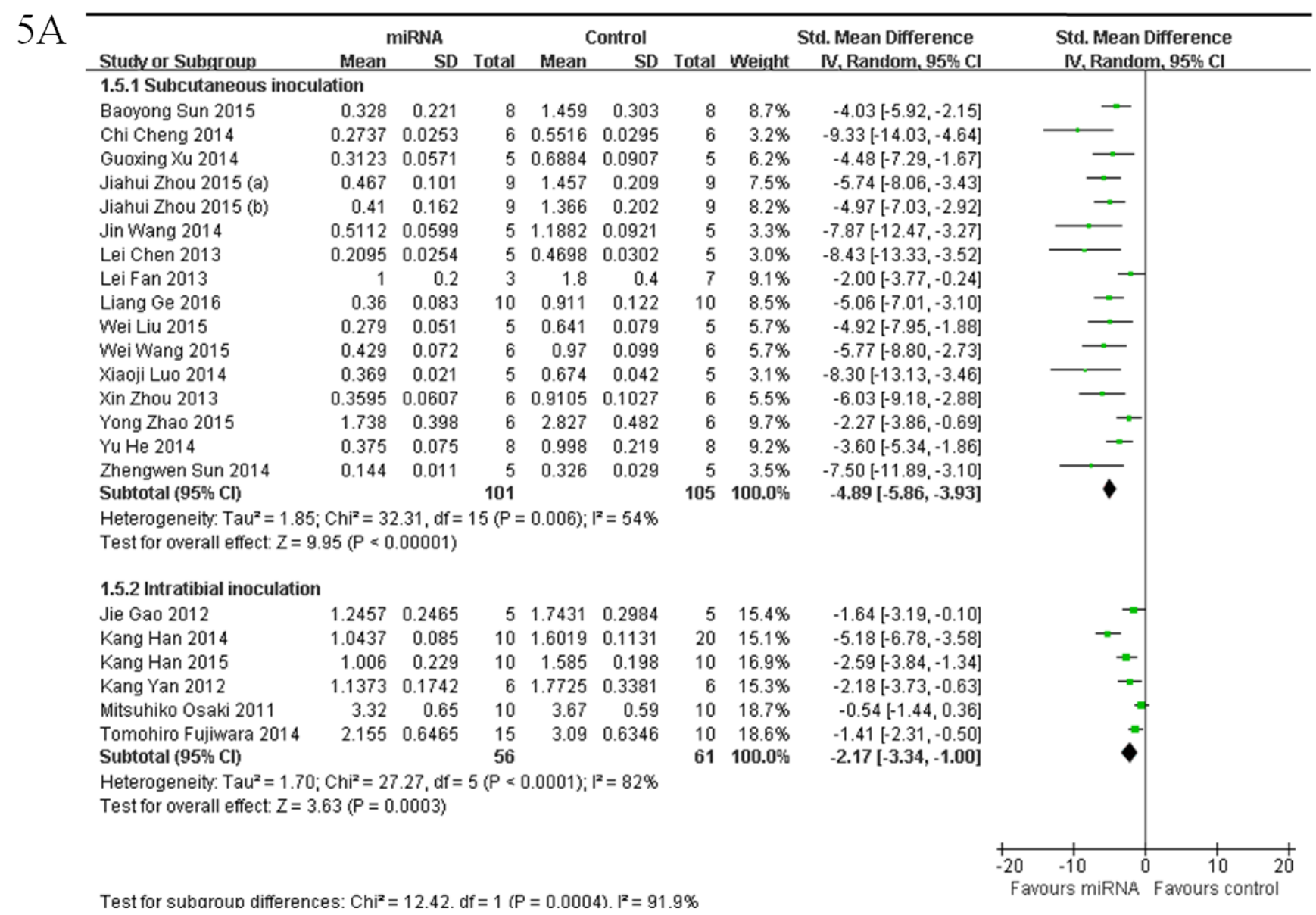

$5 \mathrm{~B}$

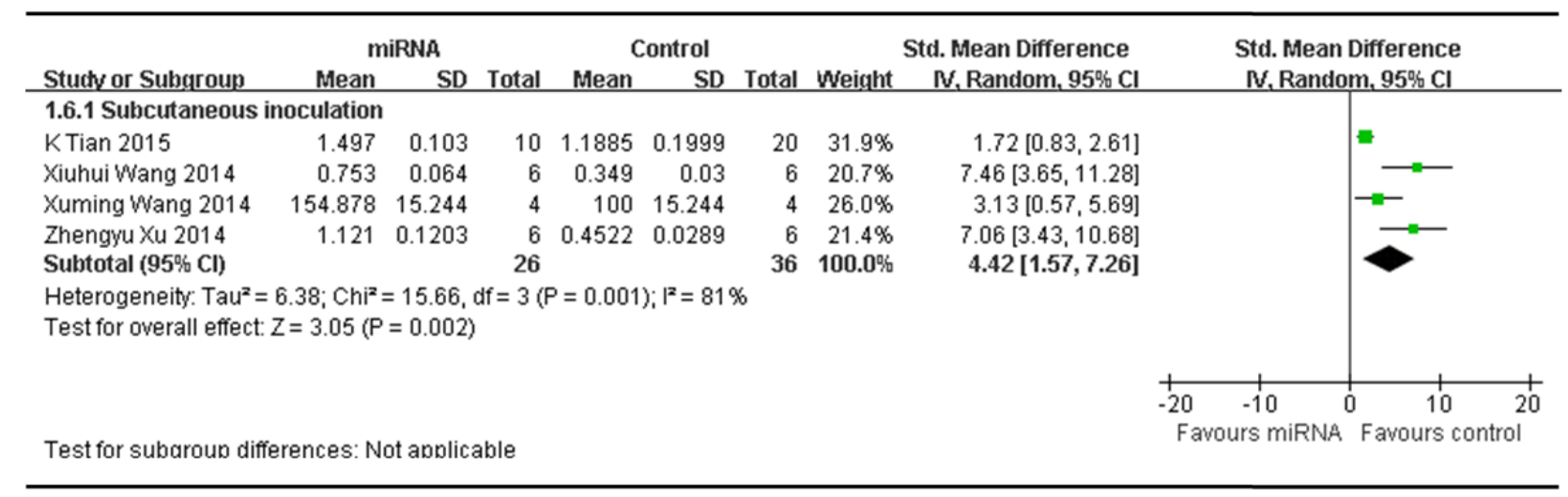

Figure 5: Meta-analysis of included studies evaluating the inhibitory effects on tumor weight after the aberrantly expressed miRNAs were corrected, when studies reported miRNAs as tumor suppressors A. or oncogenes B. used tumor weight as the major outcome measure were stratified by injection sites of osteosarcoma cells. SD, standard deviation; CI, confidence interval. 
the OS xenograft models were produced by subcutaneous injection than by intratibial injection.

There were 4 studies reported tumor weight as the major outcome measure and miRNAs as oncogenes, which used OS xenograft models produced by subcutaneous inoculation of OS cells [34, 49-51]. There were 26 mice in the intervention arm and 36 in the control arm. Given that the heterogeneity was high among the studies, a random-effects model was selected, and the tumor weight considerably decreased when the expressions of the oncogene miRNAs were corrected (pooled MD = [4.42]; 95\% confidence interval [CI]: [1.57]- [7.26]; $p=0.001$; Figure 5B).

Inoculated osteosarcoma cell lines

The delaminating analysis based on the 5 different OS cell lines that were used to produce OS xenograft models in the included studies, were performed. Given that the heterogeneity was high across the studies, a random-effects model was chosen. Among studies reported tumor weight as the major outcome measure and miRNAs as tumor suppressors, 5 studies [53, 54, $58,59,65]$, used MG-63 for OS xenograft model, were combined together for the meta-analysis, and there were 34 mice in the intervention and 38 mice in the control arm. Tumor weight significantly decreased when the aberrantly expressed miRNAs were corrected (pooled MD = [ -3.97]; $95 \%$ confidence interval $[\mathrm{CI}]:[-5.39]-[-2.55] ; p=0.06$; Figure 6A, part 1); data from the 3 studies [44-46] used U2 OS for OS xenograft model, were combined together for the meta-analysis, and there were 20 mice in both the intervention and control arms. Tumor weight significantly decreased when the aberrantly expressed miRNAs were corrected (pooled MD $=[-6.90] ; 95 \%$ confidence interval [CI]: [-9.88]- [-3.91]; $p=0.15$; Figure 6A,part 2); data from the 3 studies [32, 46, 55] used Saos-2 for OS xenograft model, were combined together for the metaanalysis, and there were 20 mice in both the intervention and control arms. Tumor weight significantly decreased when the aberrantly expressed miRNAs were corrected (pooled $\mathrm{MD}=[-5.59] ; 95 \%$ confidence interval $[\mathrm{CI}]$ : [-7.18]- [-4.00]; $p=0.87$; Figure 6A, part 3); data from the 5 studies $[17,37,43,47,61]$ used $143 \mathrm{~B}$ for OS xenograft model, were combined together for the meta-analysis, and there were 42 mice in the intervention arm and 37 in the control arm. Tumor weight noticeably decreased when the aberrantly expressed miRNAs were corrected (pooled MD $=[-2.53] ; 95 \%$ confidence interval $[\mathrm{CI}]:[-4.11]-[-0.96]$; $p=0.0004$; Figure 6A, part 4); data from the 3 studies [33, $42,62]$ used SOSP-9607 for OS xenograft model, were combined together for the meta-analysis, and there were 26 mice in the intervention arm and 36 in the control arm. Tumor weight significantly decreased when the aberrantly expressed miRNAs were corrected (pooled MD = [-3.28]; $95 \%$ confidence interval $[\mathrm{CI}]:[-5.02]-[-1.55] ; p=0.01$; Figure 6A, part 5).
As we could see in Figure 6A, the overall effects on reducing the tumor weight were most significant when the OS xenograft models were produced by injection of U2 OS cells, then by injection of Saos-2, and followed by injection of MG-63, then143B or SOSP-9607.

There were 3 studies reported tumor weight as the major outcome measure and miRNAs as oncogenes, used Saos-2 for OS xenograft model, were combined together for the meta-analysis, and there were 16 mice in both the intervention and control arms $[34,49,50]$. Tumor weight significantly decreased when the aberrantly expressed miRNAs were corrected (pooled $\mathrm{MD}=[5.61] ; 95 \%$ confidence interval [CI]: [2.64]- [8.58]; $p=0.09$; Figure 6B).

\section{When all the included studies used tumor volume as the major outcome measure were stratified by whether the abnormally expressed miRNAs function as oncogenes or tumor suppressors in the pathogenesis of osteosarcoma}

Thirty-one studies that included measurements of tumor volume were divided into 2 subgroups according to the function of abnormally expressed miRNAs.

One subgroup included 28 studies, which reported that miRNAs function as the tumor suppressors, and thus the data were combined for a meta-analysis $[25,33$, $35-42,44,45,47,48,52-65]$ A total of 195 mice in the intervention arm and 242 in the control arm were included. The tumor volume was considerably suppressed after the decreased miRNAs were restored in a random-effects model. And the pooled MD $=[-4.65] ; 95 \%$ confidence interval [CI]: [-5.43]- [-3.88]; $p<0.00001$; Figure 7, upper part).

The 3 studies reported that miRNAs function as oncogenes in OS as described above, and thus the data were combined for a meta-analysis $[34,50,51]$. A total of 20 mice in the intervention arm and 30 in the control arm were included. The tumor volume was considerably suppressed after the aberrantly expressed miRNAs were restored in a random-effects model. And the pooled MD $=[3.88] ; 95 \%$ confidence interval $[\mathrm{CI}]:[0.48]-[7.27] ; p=$ 0.005 ( Figure 7, lower part).

\section{When above included studies that reported miRNAs as tumor suppressors or oncogenes were further stratified respectively by the following factors:}

The miRNA delivery method

There were 28 studies which reported that tumor volume as the major outcome measure and miRNAs as tumor suppressors. MiRNAs were directly transfected into the OS cells in 10 studies, and thus the data were combined for a meta-analysis [40, 41, 44, 48, 54-57, 59, 65] There were 76 mice in the intervention arm and 90 mice in the control arm. The tumor volume showed a statistically 
$6 \mathrm{~A}$

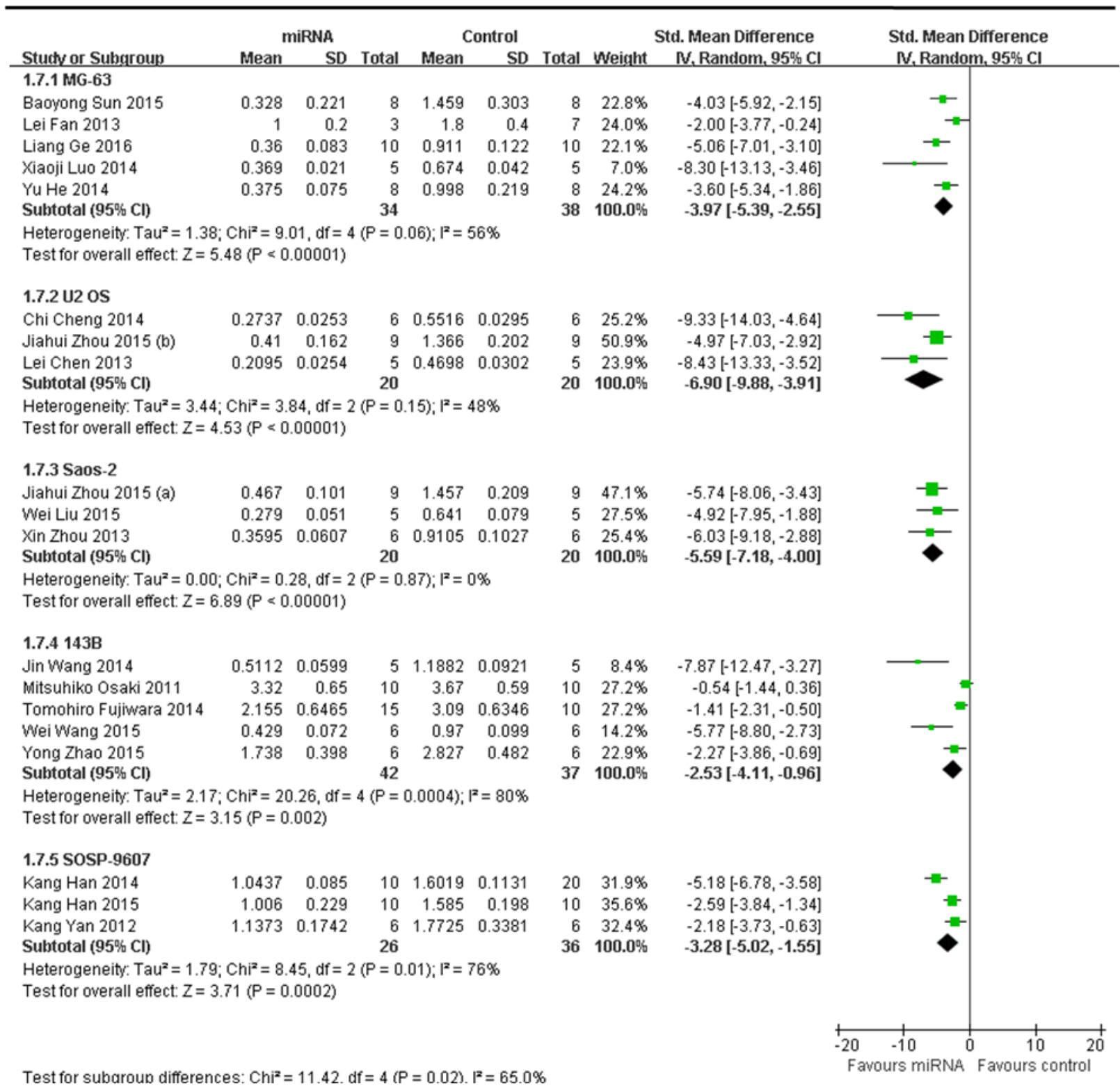

$6 B$

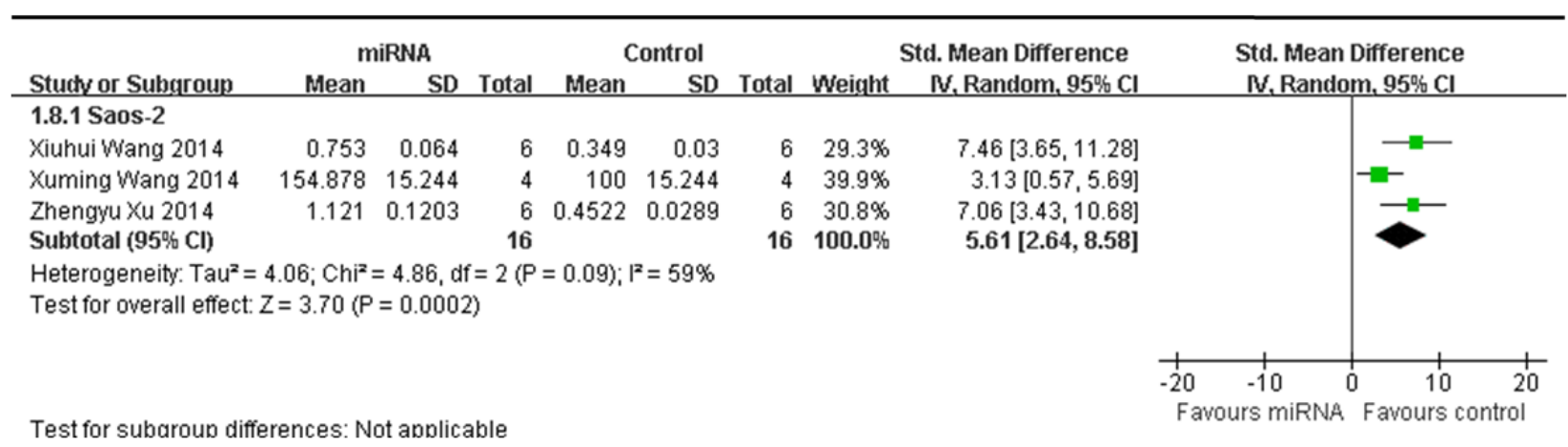

Figure 6: Meta-analysis of included studies evaluating the inhibitory effects on tumor weight after the aberrantly expressed miRNAs were corrected, when studies reported miRNAs as tumor suppressors A. or oncogenes B. and used tumor weight as the major outcome measure, were stratified by osteosarcoma cell lines used to produce osteosarcoma xenograft models . SD, standard deviation; CI, confidence interval. 
significant difference when the decreased miRNAs were corrected (pooled MD $=[-4.48] ; 95 \%$ confidence interval [CI]: [-5.60]- [-3.36]; $p=0.001$; Figure 8A, part 1) in a random-effects model. MiRNAs with vectors of plasmids were transfected into the OS cells in 6 studies, and were combined for a meta-analysis. There were 40 mice in the intervention arm and 57 in the control arm. The tumor volume significantly reduced when the decreased tumor suppressor miRNAs were corrected (pooled MD $=[$ $-4.01]$; 95\% confidence interval [CI]: [-5.89]- [-2.13]; $p<0.00001$; Figure 8A, part 2)in a random-effects model [33, 35, 36, 60, 63, 64]. MiRNAs were infected into the OS cells by lentivirus vectors in 8 studies, and were combined for a meta-analysis. There were 53 mice in the intervention arm and 63 in the control arm. The tumor volume significantly decreased when the decreased tumor suppressor miRNAs were corrected (pooled MD = [-5.50]; 95\% confidence interval [CI]: [-6.67]- [-4.32]; $p$ $=0.21$; Figure $8 \mathrm{~A}$, part 3 )in a random-effects model [25, $37,38,42,45,53,61,62]$. MiRNAs were injected into tumor directly in 3 studies, and were combined for a metaanalysis. There were 20 mice in the intervention arm and 26 in the control arm. The tumor volume significantly decreased when the aberrantly expressed miRNAs were corrected (pooled $\mathrm{MD}=[-5.40] ; 95 \%$ confidence interval [CI]: [-8.80]- [-1.99]; $p=0.002$; Figure $8 \mathrm{~A}$, part 4) in a random-effects model $[39,52,58]$.

Only one study reported that miRNA was delivered

\begin{tabular}{|c|c|c|c|c|c|c|c|c|c|c|}
\hline \multirow[b]{2}{*}{ Stucty or Subqroup } & \multicolumn{2}{|c|}{ miRNA } & \multicolumn{4}{|c|}{ Control } & \multicolumn{2}{|r|}{ Std. Mean Difference } & \multirow{2}{*}{\multicolumn{2}{|c|}{$\begin{array}{l}\text { Std. Mean Difference } \\
\text { N, Random, } 95 \% \mathrm{Cl}\end{array}$}} \\
\hline & Mean & SD & Total & Mean & SD & Total & Weight & N, Random, $95 \% \mathrm{Cl}$ & & \\
\hline \multicolumn{11}{|l|}{ 2.1.1 Tumor suppressor } \\
\hline Baoyong Sun 2015 & 58.667 & 14.667 & 8 & 310.667 & 32 & 8 & $2.2 \%$ & $-9.57[-13.52,-5.63]$ & 一 & \\
\hline Chi Cheng 2014 & 220.7254 & 24.8705 & 6 & 478.7565 & 43.5233 & 6 & $2.5 \%$ & $-6.72[-10.19,-3.25]$ & 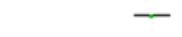 & \\
\hline Fang Ji 2013 (a) & 0.09 & 0.0707 & 4 & 0.3004 & 0.0755 & 4 & $3.6 \%$ & $-2.50[-4.71,-0.29]$ & $\rightarrow$ & \\
\hline Fang Ji 2013 (b) & 0.0699 & 0.0554 & 4 & 0.2313 & 0.059 & 4 & $3.6 \%$ & $-2.45[-4.64,-0.27]$ & $\rightarrow$ & \\
\hline Guodong Li 2013 & 0.1558 & 0.0183 & 6 & 0.2602 & 0.0256 & 12 & $3.9 \%$ & $-4.22[-6.06,-2.38]$ & - & \\
\hline Guoqing Duan 2015 & 284.71 & 17.91 & 7 & 310.825 & 46.269 & 7 & $4.6 \%$ & $-0.70[-1.79,0.39]$ & & \\
\hline Guoxing Xu 2014 & 373.1343 & 48.5075 & 5 & 813.4328 & 97.0149 & 5 & $2.7 \%$ & $-5.19[-8.36,-2.01]$ & - & \\
\hline Hao Zhang 2010 (a) & 0.04 & 0.0323 & 6 & 0.2892 & 0.0723 & 6 & $3.5 \%$ & $-4.11[-6.41,-1.81]$ & - & \\
\hline Hao Zhang 2010 (b) & 0.029 & 0.0243 & 6 & 0.2293 & 0.0579 & 6 & $3.5 \%$ & $-4.16[-6.49,-1.84]$ & - & \\
\hline Jie Gao 2012 & 110.3728 & 53.4846 & 5 & 226.094 & 59.8055 & 5 & $4.1 \%$ & $-1.84[-3.46,-0.23]$ & - & \\
\hline Jie Jln 2013 & 584.0426 & 63.2405 & 5 & $1,449.6658$ & 161.5369 & 10 & $3.2 \%$ & $-5.87[-8.53,-3.20]$ & $\rightarrow$ & \\
\hline Jin Wang 2014 & 686.8421 & 94.7368 & 5 & $1,509.8684$ & 159.8684 & 5 & $2.5 \%$ & $-5.66[-9.07,-2.24]$ & - & \\
\hline Kang Han 2014 & $1,487.8049$ & 195.122 & 10 & $2,560.9756$ & 263.9395 & 20 & $4.3 \%$ & $-4.28[-5.67,-2.89]$ & - & \\
\hline Kang Han 2015 & $1,424.242$ & 212.121 & 10 & $2,545.455$ & 272.727 & 10 & $4.0 \%$ & $-4.40[-6.15,-2.64]$ & - & \\
\hline Kang Yan 2012 & $1,007.3382$ & 110.2941 & 6 & $1,580.8676$ & 102.9412 & 6 & $3.1 \%$ & $-4.96[-7.64,-2.29]$ & - & \\
\hline Lei Chen 2013 & 269.906 & 32.9154 & 5 & 642.9467 & 57.0533 & 5 & $2.0 \%$ & $-7.23[-11.49,-2.98]$ & - & \\
\hline Lei Fan 2013 & 1.1 & 0.2 & 8 & 1.6 & 0.3 & 8 & $4.5 \%$ & $-1.85[-3.08,-0.63]$ & - & - \\
\hline Lei Song 2013 & 542.3744 & 82.0669 & 4 & $1,442.612$ & 114.8936 & 4 & $1.4 \%$ & $-7.84[-13.41,-2.27]$ & - & \\
\hline Liang Ge 2016 & 385.761 & 75.081 & 10 & 755.987 & 54.369 & 10 & $3.7 \%$ & $-5.41[-7.48,-3.34]$ & - & \\
\hline Masanori Kawano 2015 & 94.739 & 22.291 & 7 & 225.2355 & 20.0791 & 14 & $3.6 \%$ & $-6.02[-8.24,-3.81]$ & - & \\
\hline Meng Xu 2014 & 766.949 & 88.983 & 8 & $1,360.169$ & 114.407 & 8 & $3.4 \%$ & $-5.47[-7.87,-3.08]$ & - & \\
\hline Tatsuya Iwasaki 2015 & 104.979 & 31.579 & 7 & 258.5315 & 19.4387 & 14 & $3.5 \%$ & $-6.16[-8.41,-3.90]$ & - & \\
\hline Wei Liu 2015 & 200 & 40.476 & 5 & 459.524 & 64.286 & 5 & $3.1 \%$ & $-4.36[-7.12,-1.61]$ & - & \\
\hline Wei Wang 2015 & 0.718 & 0.102 & 6 & 1.426 & 0.141 & 6 & $3.0 \%$ & $-5.31[-8.14,-2.48]$ & $\sim$ & \\
\hline Xiaohui Sun 2015 & $1,356.522$ & 513.043 & 6 & $2,695.652$ & 373.913 & 6 & $4.0 \%$ & $-2.75[-4.51,-1.00]$ & - & \\
\hline Xiaoji Luo 2014 & 152.607 & 21.739 & 5 & 415.651 & 32.609 & 5 & $1.6 \%$ & $-8.57[-13.56,-3.59]$ & - & \\
\hline Xinyu Wu 2013 (a) & 755.0336 & 40.2685 & 6 & $1,147.651$ & 76.2622 & 12 & $3.5 \%$ & $-5.57[-7.85,-3.29]$ & - & \\
\hline xinyu Wu 2013 (b) & 785.2349 & 35.2349 & 6 & $1,218.1208$ & 92.2791 & 12 & $3.6 \%$ & $-5.22[-7.38,-3.05]$ & - & \\
\hline Yong Zhao 2015 & $1,618.497$ & 624.277 & 6 & $3,445.087$ & 508.671 & 6 & $3.9 \%$ & $-2.96[-4.80,-1.13]$ & & \\
\hline Yu He 2014 & 0.328 & 0.058 & 8 & 1.009 & 0.052 & 8 & $1.7 \%$ & $-11.69[-16.46,-6.92]$ & 一 & \\
\hline Zhengwen Sun 2014 & 210.035 & 23.123 & 5 & 521.147 & 52.553 & 5 & $2.1 \%$ & $-6.92[-11.01,-2.83]$ & 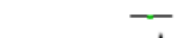 & \\
\hline Subtotal $(95 \% \mathrm{Cl})$ & & & 195 & & & 242 & $100.0 \%$ & $-4.65[-5.43,-3.88]$ & 1 & \\
\hline \multicolumn{11}{|c|}{$\begin{array}{l}\text { Heterogeneity: } \mathrm{Tau}^{2}=3.13 ; \mathrm{Chi}^{2}=106.69, \mathrm{df}=30(P<0.00001) ; \mathrm{I}^{2}=72 \% \\
\text { Test for overall effect: } Z=11.74(P<0.00001)\end{array}$} \\
\hline \multicolumn{11}{|l|}{ 2.1.2 Oncogenesis } \\
\hline K Tian 2015 & $2,019.231$ & 384.615 & 10 & $1,557.692$ & 274.316 & 20 & $41.2 \%$ & $1.43[0.58,2.28]$ & & 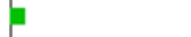 \\
\hline Xuming Wang 2014 & 1.211 & 0.073 & 4 & 0.766 & 0.078 & 4 & $27.7 \%$ & $5.12[1.34,8.91]$ & & - \\
\hline Zhengyu Xu 2014 & $1,358.9041$ & 142.4658 & 6 & 624.6575 & 71.2329 & 6 & $31.0 \%$ & $6.02[2.87,9.17]$ & & $=$ \\
\hline Subtotal $(95 \% \mathrm{Cl})$ & & & 20 & & & 30 & $100.0 \%$ & $3.88[0.48,7.27]$ & & \\
\hline \multicolumn{11}{|c|}{$\begin{array}{l}\text { Heterogeneity: } \text { Tau }^{2}=7.09 ; \mathrm{Chi}^{2}=10.52, \mathrm{df}=2(P=0.005) ; \mathrm{I}^{2}=81 \% \\
\text { Test for overall effect: } Z=2.24(P=0.03)\end{array}$} \\
\hline Test for subaroun differ & es: $\mathrm{Chi}^{2}=2$ & .04. $d f=1$ & 0. & 01). $\left.\right|^{2}=9$ & & & & & $\begin{array}{cc}1 & 1 \\
-20 & -10 \\
\text { Favours miRNA }\end{array}$ & $\begin{array}{l}1 \\
0 \\
0\end{array} \frac{1}{10} 20$ \\
\hline
\end{tabular}

Figure 7: Meta-analysis of studies evaluating the inhibitory effects on tumor volume after the aberrantly expressed miRNAs were corrected, when all included studies used tumor volume as the major outcome measure were stratified by the function of miRNAs in the pathogenesis of osteosarcoma. SD, standard deviation; CI, confidence interval. 
by the tail vain [47].

As we could see in Figure 8A, the overall effects on reducing the tumor volume showed no significant difference among different miRNA delivery methods, with a slight better of miRNAs being infected with lentivirus vectors or injected into tumor directly, then being directly transfected into OS cells or transfected with plasmid vectors.
There were 3 studies which reported that tumor volume as the major outcome measure and miRNAs as oncogenes. MiRNAs were transfected into OS cells with plasmid vectors in 2 studies, and the data were combined for a meta-analysis $[49,51]$. There were 14 mice in the intervention arm and 24 in the control arm. Tumor volume was also significantly inhibited after correction of the oncogene miRNA expression (pooled $\mathrm{MD}=[2.80]$; $95 \%$

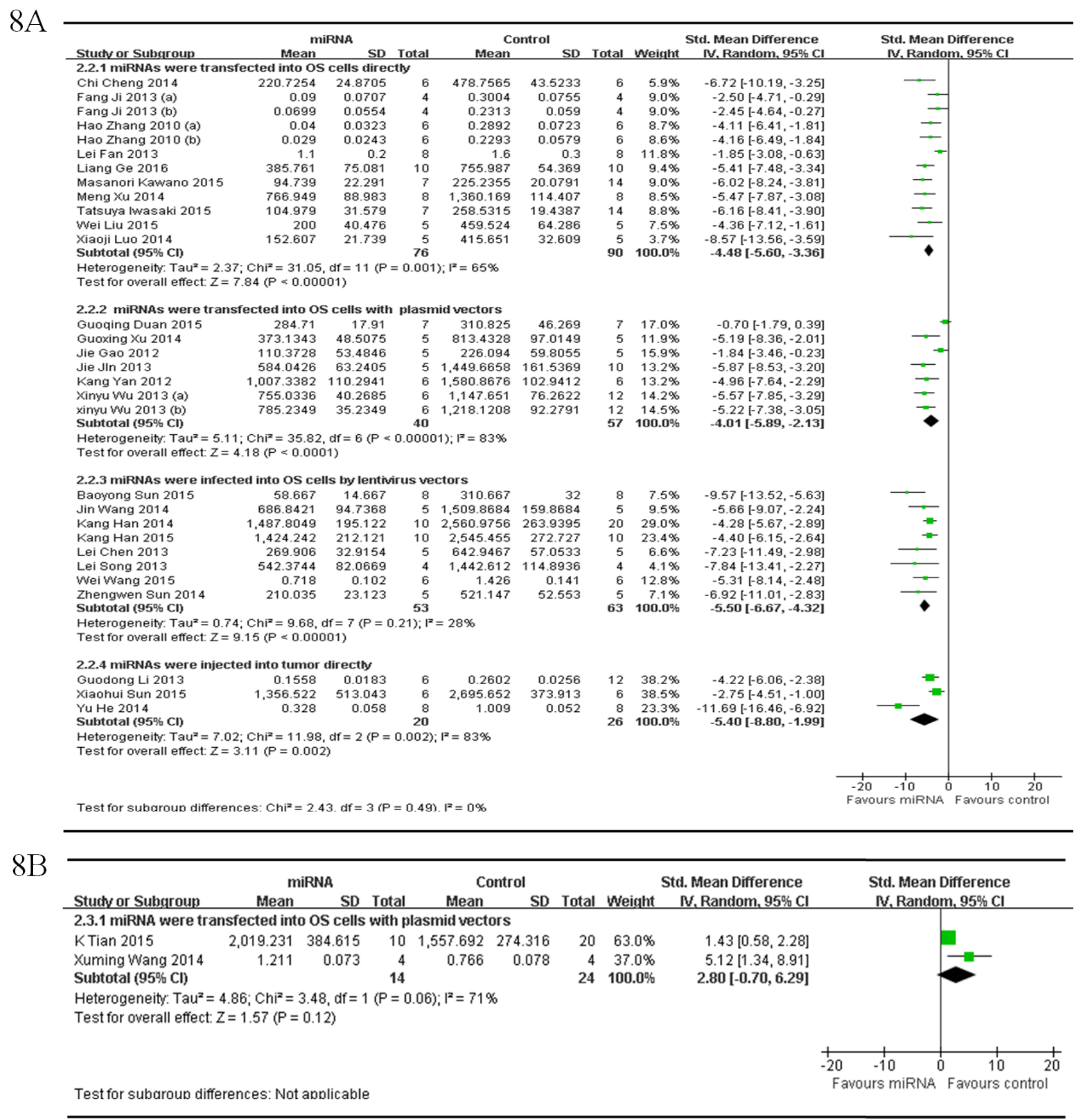

Figure 8: Meta-analysis of included studies evaluating the inhibitory effects on tumor volume after the aberrantly expressed miRNAs were corrected, when studies reported miRNAs as tumor suppressors A. or oncogenes B. and used tumor volume as the major outcome measure were stratified by the miRNA delivery method. SD, standard deviation; CI, confidence interval. 
confidence interval [CI]: [-0.70]- [6.29]; $p=0.06$; Figure $8 \mathrm{~B})$ in a random-effects model.

Only 1 study reported that miRNA was infected into the OS cells by lentivirus vectors as being described above [34].

\section{The names of miRNAs}

In order to find out if different miRNA has different influence on OS growth, data of same miRNA from more than 2 studies (if have), which reported that tumor volume was the major outcome measure, were combined together for a meta-analysis. This resulted 5 different miRNAs were analyzed, including 4 tumor suppressor miRNAs(miR-195, miR-143, miR-34a and miR-133) and loncogene(miR-214).There were 15 mice in the intervention arm and 15 in the control arm. Tumor volume significantly decreased when the expression of down-regulated miR-195 was recovered (pooled MD = [
$-3.10] ; 95 \%$ confidence interval [CI]: $[-5.60]-[-0.59] ; p$ $=0.04$; Figure 9, part 1) $[62,64]$. There were 12 mice in the intervention arm and 12 in the control arm. Tumor volume significantly decreased when the expression of down-regulated miR-143 was recovered (pooled MD = [-4.14]; 95\% confidence interval [CI]: [-5.77]- [-2.50]; $p=$ 0.97; Figure 9, part 2) [41] .There were 24 mice in the intervention arm and 36 in the control arm. Tumor volume significantly decreased when the expression of downregulated miR-34a was recovered (pooled $\mathrm{MD}=[-4.53]$; 95\% confidence interval [CI]: [-5.81]- [-3.24]; $p=0.25$; Figure 9, part 3) $[33,36,47]$.There were 8 mice in the intervention arm and 8 in the control arm. Tumor volume there no significantly decreased when the miR-133a was recovered (pooled $\mathrm{MD}=[-2.48] ; 95 \%$ confidence interval [CI]: [-4.03]- [-0.92]; $p=0.92$; Figure 9, part 4) [40]. There were 10 mice in the intervention arm and 10 in the

\begin{tabular}{|c|c|c|c|c|c|c|c|c|c|c|}
\hline \multirow[b]{2}{*}{ Studv or Subgroup } & \multicolumn{2}{|c|}{ miRNA } & \multicolumn{3}{|c|}{ Control } & \multirow[b]{2}{*}{ Total } & \multicolumn{2}{|r|}{ Std. Mean Difference } & \multirow{2}{*}{\multicolumn{2}{|c|}{$\begin{array}{l}\text { Std. Mean Difference } \\
\text { N. Random, } 95 \% \mathrm{Cl}\end{array}$}} \\
\hline & Mean & SD & Iotal & Mean & SD & & Weight & N. Random, $95 \% \mathrm{Cl}$ & & \\
\hline \multicolumn{11}{|l|}{ 2.4.1 miR-195 } \\
\hline Jie Gao 2012 & 110.3728 & 53.4846 & 5 & 226.094 & 59.8055 & 5 & $50.9 \%$ & $-1.84[-3.46,-0.23]$ & 뭅 & \\
\hline Kang Han 2015 & $1,424.242$ & 212.121 & 10 & $2,545.455$ & 272.727 & 10 & $49.1 \%$ & $-4.40[-6.15,-2.64]$ & 들 & \\
\hline Subtotal $(95 \% \mathrm{Cl})$ & & & 15 & & & 15 & $100.0 \%$ & $-3.10[-5.60,-0.59]$ & & \\
\hline \multicolumn{11}{|c|}{$\begin{array}{l}\text { Heterogeneity: } \mathrm{Tau}^{2}=2.52 ; \mathrm{Chi}^{2}=4.40, \mathrm{df}=1(P=0.04) ; \mathrm{I}^{2}=77 \% \\
\text { Test for overall effect: } Z=2.43(P=0.02)\end{array}$} \\
\hline \multicolumn{11}{|l|}{ 2.4.2 miR-143 } \\
\hline Hao Zhang 2010 (a) & 0.04 & 0.0323 & 6 & 0.2892 & 0.0723 & 6 & $50.5 \%$ & $-4.11[-6.41,-1.81]$ & + & \\
\hline Hao Zhang 2010 (b) & 0.029 & 0.0243 & 6 & 0.2293 & 0.0579 & 6 & $49.5 \%$ & $-4.16[-6.49,-1.84]$ & 늠 & \\
\hline Subtotal $(95 \% \mathrm{Cl})$ & & & 12 & & & 12 & $100.0 \%$ & $-4.14[-5.77,-2.50]$ & $\boldsymbol{\nabla}$ & \\
\hline \multicolumn{11}{|c|}{$\begin{array}{l}\text { Heterogeneity: } \text { Tau }^{2}=0.00 ; \mathrm{Chi}^{2}=0.00, \mathrm{df}=1(P=0.97) ; \mathrm{I}^{2}=0 \% \\
\text { Test for overall effect: } Z=4.95(P<0.00001)\end{array}$} \\
\hline \multicolumn{11}{|l|}{ 2.4.3 miR-34a } \\
\hline Kang Yan 2012 & $1,007.3382$ & 110.2941 & 6 & $1,580.8676$ & 102.9412 & 6 & $18.5 \%$ & $-4.96[-7.64,-2.29]$ & -1 & \\
\hline Xinyu Wu 2013 (a) & 755.0336 & 40.2685 & 6 & $1,147.651$ & 76.2622 & 12 & $23.7 \%$ & $-5.57[-7.85,-3.29]$ & $\rightarrow$ & \\
\hline xinyu Wu 2013 (b) & 785.2349 & 35.2349 & 6 & $1,218.1208$ & 92.2791 & 12 & $25.6 \%$ & $-5.22[-7.38,-3.05]$ & $\rightarrow$ & \\
\hline Yong Zhao 2015 & $1,618.497$ & 624.277 & 6 & $3,445.087$ & 508.671 & 6 & $32.2 \%$ & $-2.96[-4.80,-1.13]$ & - & \\
\hline Subtotal $(95 \% \mathrm{Cl})$ & & & 24 & & & 36 & $100.0 \%$ & $-4.53[-5.81,-3.24]$ & $\bullet$ & \\
\hline \multicolumn{11}{|c|}{$\begin{array}{l}\text { Heterogeneity: } \text { Tau }^{2}=0.46 ; \mathrm{Ch}^{2}=4.08, \mathrm{df}=3(P=0.25) ; \mathrm{I}^{2}=26 \% \\
\text { Test for overall effect: } Z=6.91(P<0.00001)\end{array}$} \\
\hline \multicolumn{11}{|l|}{ 2.4.4 miR-133a } \\
\hline Fang Ji 2013 (a) & 0.09 & 0.0707 & 4 & 0.3004 & 0.0755 & 4 & $49.4 \%$ & $-2.50[-4.71,-0.29]$ & 븜 & \\
\hline Fang Ji 2013 (b) & 0.0699 & 0.0554 & 4 & 0.2313 & 0.059 & 4 & $50.6 \%$ & $-2.45[-4.64,-0.27]$ & 듬다 & \\
\hline Subtotal $(95 \% \mathrm{Cl})$ & & & 8 & & & 8 & $100.0 \%$ & $-2.48[-4.03,-0.92]$ & $\boldsymbol{\nabla}$ & \\
\hline \multicolumn{11}{|c|}{$\begin{array}{l}\text { Heterogeneity: } \text { Tau }^{2}=0.00 ; C h i^{2}=0.00, d f=1(P=0.98) ; I^{2}=0 \% \\
\text { Test for overall effect: } Z=3.13(P=0.002)\end{array}$} \\
\hline \multicolumn{11}{|l|}{ 2.4.5 miR-214 } \\
\hline Xuming Wang 2014 & 1.211 & 0.073 & 4 & 0.766 & 0.078 & 4 & $40.9 \%$ & $5.12[1.34,8.91]$ & & - \\
\hline Zhengyu Xu 2014 & $1,358.9041$ & 142.4658 & 6 & 624.6575 & 71.2329 & 6 & $59.1 \%$ & $6.02[2.87,9.17]$ & & - \\
\hline Subtotal $(95 \% \mathrm{Cl})$ & & & 10 & & & 10 & $100.0 \%$ & $5.65[3.23,8.07]$ & & \\
\hline \multicolumn{11}{|c|}{$\begin{array}{l}\text { Heterogeneity: } \mathrm{Tau}^{2}=0.00 ; \mathrm{Chi}^{2}=0.13, \mathrm{df}=1(\mathrm{P}=0.72) ; \mathrm{I}^{2}=0 \% \\
\text { Test for overall effect: } Z=4.58(P<0.00001)\end{array}$} \\
\hline Test for subaroun diff & rences: $\mathrm{Chi}^{2}=$ & : $56.58 . d f=$ & $4(P<C$ & $0.00001)\left.\cdot\right|^{2}=$ & $92.9 \%$ & & & & $\begin{array}{ccc}1 & + & + \\
-20 & -10 & 0 \\
\text { Favours miRNA }\end{array}$ & $\begin{array}{ccc} & 1 & 1 \\
0 & 10 & 20 \\
\text { Favours control }\end{array}$ \\
\hline
\end{tabular}

Figure 9: Meta-analysis of included studies evaluating the inhibitory effects on tumor volume after the aberrantly expressed miRNAs were corrected, when all included studies used tumor volume as the major outcome measure were stratified by the names of miRNAs. SD, standard deviation; CI, confidence interval. 
control arm. Tumor volume significantly decreased when the expression of up-regulated miR-214 was recovered (pooled $\mathrm{MD}=[5.65] ; 95 \%$ confidence interval [CI]: [3.23]- [8.07]; $p=0.72$; Figure 9, part 5) [34, 50].

As we could see in Figure 9, the effects on inhibiting tumor volume were most significant when the aberrantly expressed miR-34a, miR-143 and miR-214 were corrected, and then followed by miR-195 and miR-133a

Inoculation sites of osteosarcoma cells

28 studies reported tumor volume as the major outcome measure and miRNAs as tumor suppressors, were divided into 2 subgroups according to the inoculation sites

\section{$10 \mathrm{~A}$}

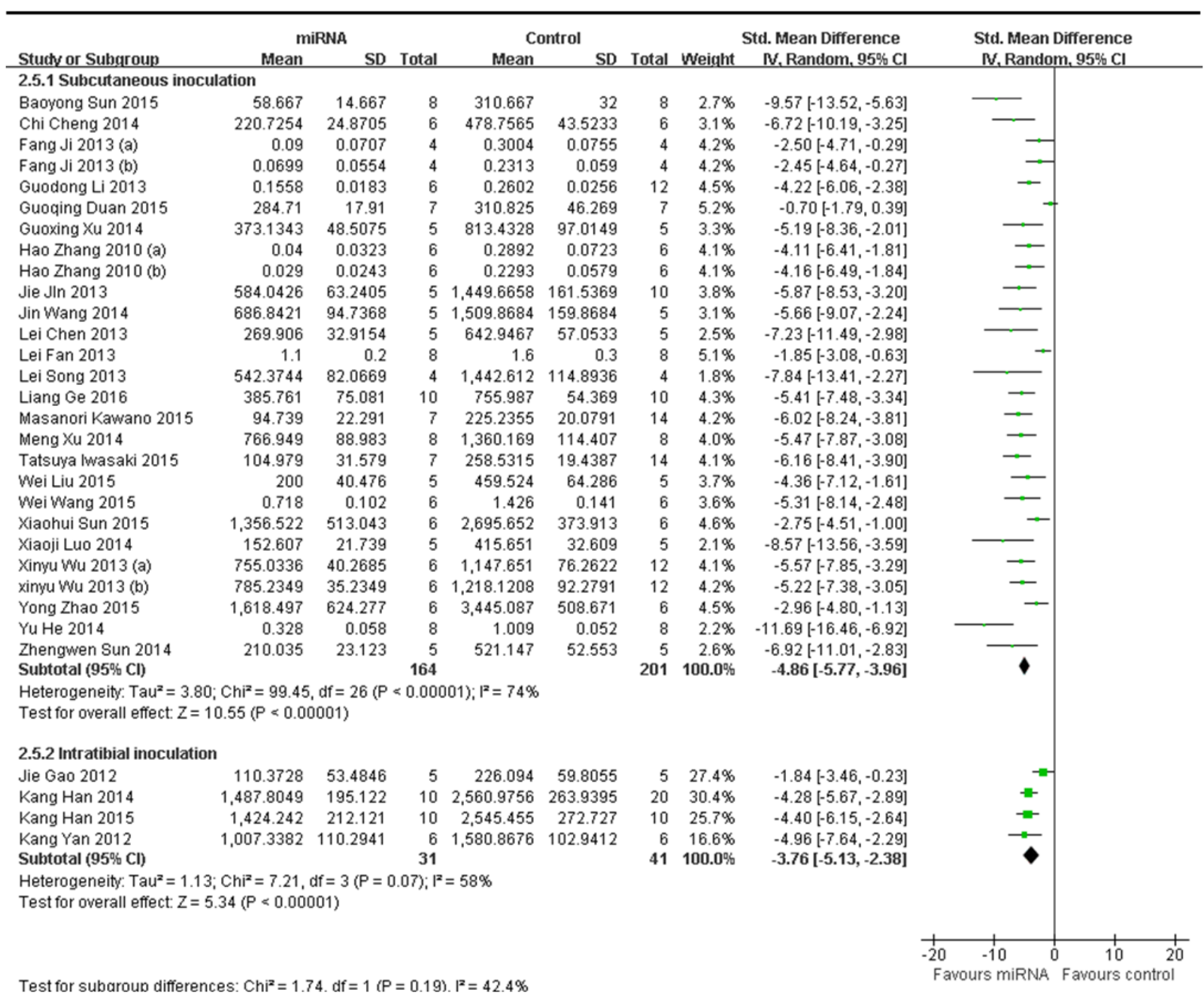

$10 \mathrm{~B}$

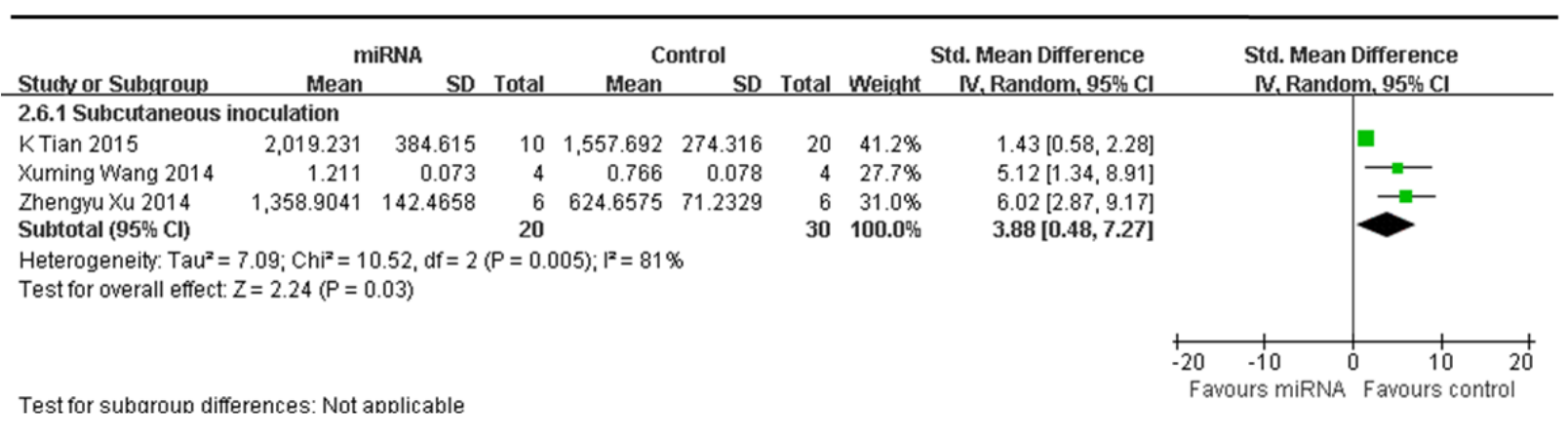

Figure 10: Meta-analysis of included studies evaluating the inhibitory effects on tumor volume after the aberrantly expressed miRNAs were corrected, when studies reported miRNAs as tumor suppressors A. or oncogenes B. and used tumor volume as the major outcome measure were stratified by injection sites of osteosarcoma cells. SD, standard deviation; CI, confidence interval. 
of OS cells.

One subgroup included 24 studies that compared the anti-osteosarcoma effects in OS xenograft models produced by subcutaneous injection, with the rectification of the abnormally expressed miRNAs $[25,35-41,44$, $45,47,48,52-61,63,65]$. There were 164 mice in the intervention arm and 201 in the control arm. The tumor volume was significantly suppressed by correcting the abnormally expressed miRNAs (pooled MD $=[-4.86]$; 95\% confidence interval [CI]: [-5.77- [-3.96]; $p<0.00001$; Figure 10A, upper part) in a random-effects model.

Another subgroup had 4 studies that compared the anti-osteosarcoma effects in OS xenograft models produced by intratibial injection, with the rectification of the abnormally expressed tumor suppressor miRNAs $[33,42,62,64]$. There were 31 mice in the intervention arm and 41 mice in the control arm. The tumor volume significantly decreased by correcting the abnormally expressed miRNAs (pooled MD $=[-3.76] ; 95 \%$ confidence interval [CI]: [-5.13]- $[-2.38] ; p=0.07$; Figure 10A, lower part) in a random-effects model.

As shown in Figure 10A, the overall effects on inhibiting tumor volume were better when the OS xenograft models were produced by subcutaneous injection than by intratibial injection.

There were 3 studies reported tumor volume as the major outcome measure and miRNAs as oncogenes, which used OS xenograft models produced by subcutaneous inoculation of OS cells $[34,50,51]$. There were 20 mice in the intervention arm and 30 in the control arm. Given that the heterogeneity was high among the studies, a random-effects model was selected, and the tumor weight considerably decreased when the expressions of the oncogene miRNAs were corrected (pooled $\mathrm{MD}=[3.88]$; 95\% confidence interval [CI]: [0.48]- [7.27]; $p=0.005$; Figure 10B).

\section{Inoculated osteosarcoma cell lines}

The delaminating analysis of data from studies reported tumor volume as the major outcome measure was performed, based on the 5 different OS cell lines for OS xenograft models in the included studies. Among studies reported miRNAs as tumor suppressors, data from the 11 studies [36, 38-41, 53, 54, 57-59, 65], which used MG-63 for OS xenograft model, were combined together for the meta-analysis, and there were 72 mice in the intervention arm and 91 mice in the control arms. Tumor volume significantly decreased by rescuing the downregulated miRNAs (pooled $\mathrm{MD}=[-5.46] ; 95 \%$ confidence interval [CI]: [-7.03]- [-3.90]; $p<0.00001$; Figure 11A, part 1) in a random-effects model; data from the 6 studies [40, $41,44,45,52,60]$, which used U2 OS for OS xenograft model, were combined together for the meta-analysis, and there were 34 mice in both the intervention and control arms. Tumor volume significantly decreased by rescuing the downregulated miRNAs (pooled $\mathrm{MD}=[-3.49] ; 95 \%$ confidence interval $[\mathrm{CI}]$ : $[-5.36]-[-1.62] ; p=0.0004$;
Figure 11A, part 2) in a random-effects model; data from the 4 studies $[36,55,56,63]$, which used Saos-2 for OS xenograft model, were combined together for the meta-analysis, and there were 23 mice in the intervention arm and 41 mice in the control arm. Tumor volume significantly decreased by rescuing the downregulated miRNAs (pooled $\mathrm{MD}=[-5.42]$; $95 \%$ confidence interval [CI]: [-6.63]- [-4.22]; $p=0.80$; Figure 11A, part 3) in a random-effects model; data from the 3 studies [37, 47, 61], which used 143B for OS xenograft model, were combined together for the meta-analysis, and there were 17 mice in both the intervention and control arms. Tumor volume significantly decreased by rescuing the downregulated miRNAs (pooled $\mathrm{MD}=[-4.23] ;$ 95\% confidence interval [CI]: [-6.05]- [-2.42]; $p=0.23$; Figure 11A, part 4) in a random-effects model; data from the 3 studies [33, 42, 62], which used SOSP-9607 for OS xenograft model, were combined together for the meta-analysis, and there were 26 mice in the intervention arm and 36 mice in the control arm. Tumor volume significantly decreased by rescuing the downregulated miRNAs (pooled MD $=[-4.42] ; 95 \%$ confidence interval [CI]: [-5.42]- [-3.41]; $p=0.91$; Figure $11 \mathrm{~A}$, part5) in a random-effects model.

As we could see in Figure 11A, the effects on reducing the tumor volume was best when the OS xenograft models were produced by injection of MG-63, then Saos-2, and followed by 143B, U2 OS or SOSP-9607.

There were 2 studies reported tumor volume as the major outcome measure and miRNAs as oncogenes, used Saos-2 for OS xenograft model, were combined together for the meta-analysis, and there were 10 mice in both the intervention and control arms [34, 50]. Tumor volume significantly decreased when the aberrantly expressed miRNAs were corrected (pooled $\mathrm{MD}=[5.65] ; 95 \%$ confidence interval [CI]: [3.23]- [8.07]; $p=0.72$; Figure 11B).

\section{DISCUSSION}

The functional contributions of miRNAs in the development and progression of malignancies have resulted in the development of new therapeutic approaches. Strategies include blocking the up-regulated oncogenic miRNAs using antisense oligonucleotides, or rescuing the downregulated cancer suppressor miRNAs by miRNA mimics [66]. MiRNAs also could be injected into the systemic circulation or introduced into the body (such as into a limb or the peritoneal cavity) or directly injected into a tumor mass [66]. On the other hand, the therapeutic agent to correct the miRNAs being abnormally regulated could be introduced into progenitor or stem cells that would be transplanted subsequently [67].

Several papers have reported that in the in vivo models, miRNAs could delay tumor formation and resulted in significantly smaller tumors when transfected into OS cells, compared with non-transfected cells. 


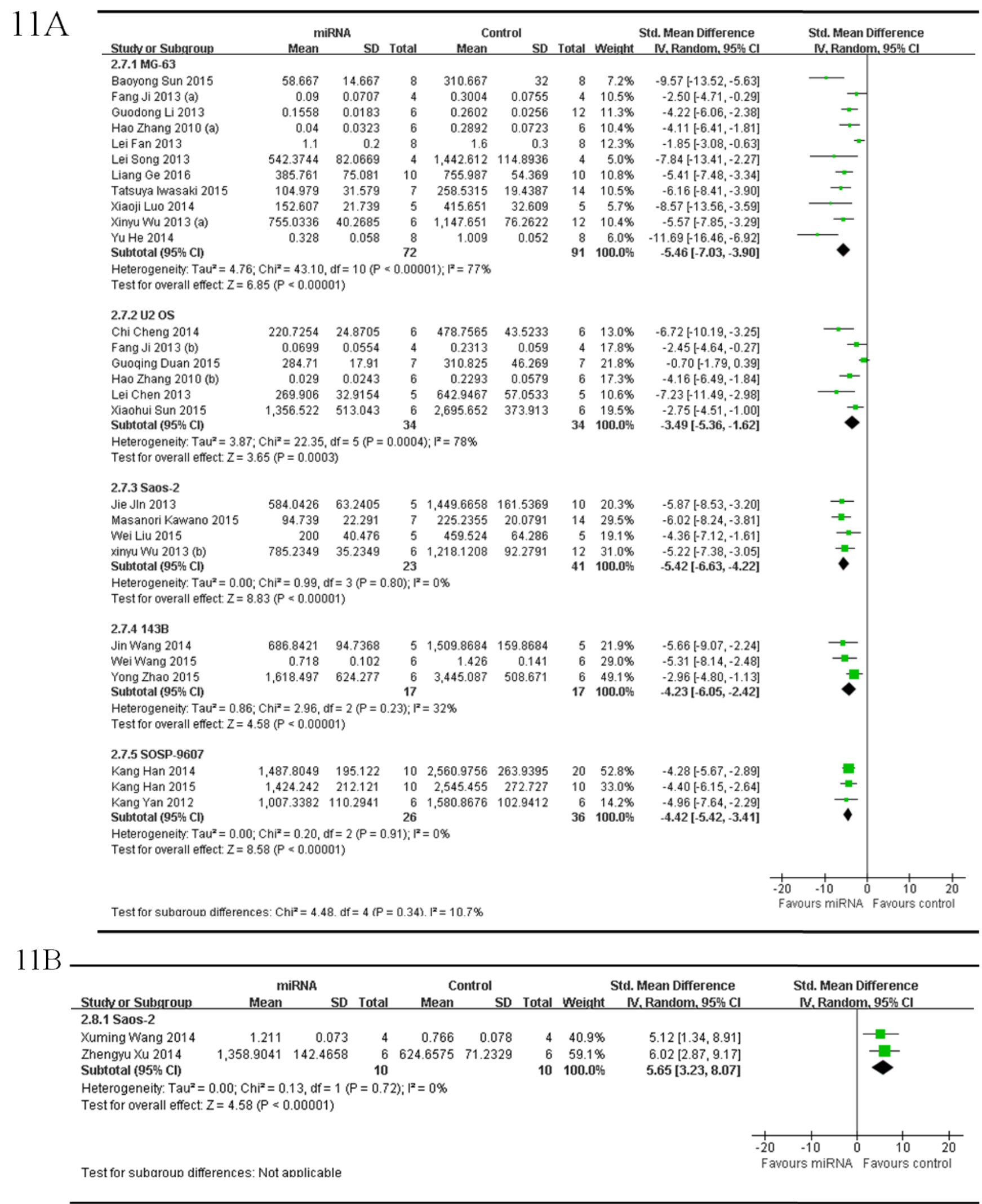

Figure 11: Meta-analysis of included studies evaluating the inhibitory effects on tumor volume after the aberrantly expressed miRNAs were corrected, when studies reported miRNAs as tumor suppressors A. or oncogenes B. and used tumor volume as the major outcome measure were stratified by osteosarcoma cell lines used to produce OS xenograft models. SD, standard deviation; CI, confidence interval. 
As well, systemic injection of miRNA/atelocollagen complexes could avoid spontaneous lung metastases in OS $[17,32-45,63-65]$. These results suggest the potential for miRNAs to be used as therapeutic targets for OS.

Since the understanding of the function of miRNAs in OS remains inadequate, we don't know if miRNAs could be directly used for the treatment of patients with OS.

In researches aimed at improving human health care, animal studies still play a crucial role in creating hypotheses that sheds light on the test in preventative or therapeutic clinical trials of new potential interventions. The underlying principle for use of animal studies is to minimize the risks to patients, since only interventions estimated prospectively safe and effective are eventually moved into clinical trials $[68,69]$.

However, the results usually vary from one study to the next, the conclusions and interpretation are not always straightforward, also no single study is executed flawlessly in all steps, the decisions about effectiveness of an intervention or validity of a hypothesis cannot be based on the results of a single animal study. Therefore, a mechanism is required to pool together the data across studies [68, 70-73].

This is the first meta-analysis to summarize the preclinical data and evaluate the potential value of miRNAs as therapeutic targets for OS. We carried out a systematic literature search that included both English and Chinese databases to make sure the comprehensiveness of the studies that were assessed. Two reviewers separately reviewed the studies, evaluated methodological quality, and extracted the data to evade the bias. This is not a comprehensive list of all therapies that has ever been tried in pre-clinical models of OS, but rather, a systematic review and meta-analysis of specific therapies that are being considered for human translation.

However, the reliability of experimental conclusions depends on the high quality experimental design, analysis and reporting. Bias occurs in the results of an animal study or the conclusions drawn from it when a systematic error exists. There are a large number of potential sources of bias, and the risks of selection bias and measurement bias, which are the most important bias, may be diminished through simple study design features, such as randomisation and blinded assessment of outcomes $[70,74]$. Unfortunately, previous research has recognized a low popularity of reporting measures to reduce the risk of bias for specific animal disease models [75-80]. Failure to depict the research methods and report data properly consequently has potential scientific, ethical, and economic meanings for the entire research procedure and the reputation of those involved in it. This is particularly right for animal research. The ARRIVE (Animal Research: Reporting of In Vivo Experiments) guidelines were developed to promote high-quality, comprehensive reporting to allow an precise critical review of what was done and found in the animal researches, which includes a checklist of 20 items describing the minimum information that all scientific publications reporting research using animals should include, for example the number and specific animal characteristics (species, strain, sex, and genetic background); detail information of housing and husbandry; and methods of the experiments, statistics and analyses (including detail methods used to reduce the bias such as randomization and blinding)."

The limitations of the included original studies were also shared in this study as any other meta-analysis. Though we searched both English and Chinese databases, we cannot confirm that all the related studies have been found. Moreover, other important reasons of bias that must be considered are discriminating reporting and publishing [81], since positive data are more likely to be published, the estimations may be overstated due to the evidence for publication bias. Meanwhile, papers published in other languages beyond English and Chinese had not been included in this manuscript due to the language barrier.

We retrieved 36 studies which met the inclusion criteria in this paper, and methodological quality of these included papers was assessed with a component method like that recommended by The Cochrane Collaboration in assessing risk of bias [82]. As we could see in Table 2, all studies reported details on the experimental procedures and animal numbers and strains used were reported except which was not clear in 1 study. Animal ages were reported in most of the studies and animal genders were reported in almost half of the studies. 23 publications described the reporting potential conflicts of interest and study funding. While only six studies reported randomization, one study reported inclusion/exclusion criteria and blinded assessment of outcome; no included studies described allocation concealment, sample-size calculation and reporting of animals excluded from analysis. The absence of above information could be caused by the real flaws in the experimental design or reporting omissions. Therefore, efforts should be made in the future to improve bioscience research design and reporting, such as using the ARRIVE guidelines.

Heterogeneity is acceptable in a meta-analysis, it would be surprising if many studies were completed by different groups in different places with different methods, all of them ended up by measuring the same fundamental parameters. Furthermore, animal studies are usually small (with a sample size of about 10 in each group). Therefore, the challenge is to decide on the most fitting approach to evaluate heterogeneous studies. When heterogeneity cannot be ignored, one analytical technique is to integrate the data into a random-effects model, which involves a hypothesis that the effects being estimated in diverse studies are not equal, however follow some distribution [83, 84]" . And more studies on a single micRNA intervention for OS are necessary in the future.

As the data of our meta-analyses were highly 
heterogeneous in terms of different cell lines and injection sites of OS cells used for generating animal models, name and function of miRNAs in the pathogenesis of OS, and different vectors were used for microRNA delivery, delaminating analyses were performed based on each of these heterogeneities to allow for evaluation of the distribution of true effects.

By the delaminating analyses based on the factors above, we further explored the effects on reducing the tumor growth, by alteration of the aberrantly expressed miRNAs. Once tumor weight and tumor volume both were taken into account, our results demonstrated that the anti-osteosarcoma effects were the best when miRNAs were infected into OS cells with lentivirus vectors, the up-regulated oncogene miR-214 was corrected or OS xenograft models were produced by subcutaneous injection. However, the inhibitory effect on tumor growth was proved to be the most poor when the OS xenograft models were produced by injection of SOSP-9607 cells. These data indicated that the therapeutic effects, by correcting the aberrantly expressed miRNAs, on OS were closely associated with the route of miRNAs being interfered, which specific miRNA being involved and the original location of the OS, and also the specific pathological type of OS. This implies intervention effect of different miRNA may possess specificity in different pathological or different original OS. So as this work provides a theoretical basis for the future individualized treatment endeavor. Nevertheless, further studies on the inherent correlation between specific miRNA and OS pathological type are necessary.

The results of this meta-analysis suggest that miRNAs are potential therapeutic targets for OS. Our results illustrated a framework for the design of animal studies and clinical trials, and for an evidence-based way to the development of new therapeutics for OS in the future. Moreover, more animal studies with the rigorous design must be carried out, wide-ranging preclinical safety and toxicity studies would be needed before a miRNAbased treatment could be translated from animal studies to human use.

\section{MATERIALS AND METHODS}

\section{Literature search strategy and selection criteria}

We systematically searched 7 databases including PubMed, Web of Science, Embase, Wan Fang Database, China Knowledge Resource Integrated Database, VIP Database, and Chinese BioMedical since their initiation date to May 10, 2016, without restrictions of the languages, publication status or publication dates. The search strategy included the following terms: (MicroRNA OR miRNA) AND osteosarcoma AND (mice OR mouse).

Two reviewers (J.L.C. and Y.M.L.) independently selected the literatures by reviewing the titles, abstracts and full texts according to the eligibility criteria. Disagreements were determined by agreement with a third author (Y.P.Y.). Only studies satisfied the criteria were included in the meta-analysis.

\section{Eligibility criteria}

\section{Types of studies}

Controlled studies that estimate the therapeutic effects on OS in mouse models by correcting the abnormally expressed miRNAs were searched. All studies only having in vitro research data and clinical case reporters were excluded.

\section{Types of participants}

Any gender, any age, or any strain of laboratory mice inoculated with OS cells via subcutaneous or intratibial injection.

\section{Types of intervention}

Any method for correcting the altered miRNA expression of OS in mouse models was included.

\section{Type of outcome measure}

Xenograft models, derived by inoculation of human cancer cells including ectopic xenograft and orthotopic xenograft according to the transplant site, play critical roles in screening new anticancer agents, evaluation the therapeutic efficacy and toxicity. Standard animal models could save money and time, and afford evidence to support clinical trials for anticancer reagents discovery [85]. Tumor volume and tumor weight are indicators used for assessing the anticancer efficacy of anticancer reagents in cancer xenograft models. Xenograft models included in this meta-analysis were produced by subcutaneous or intratibial inoculation of OS cells.

\section{Tumor volume}

Tumor volume was calculated according to the digital vernier caliper measurements using the following formula: $0.5 \times \mathrm{a} \times \mathrm{b}$, where $\mathrm{a}$ is the largest dimension and $\mathrm{b}$ is the square of perpendicular diameter [86].

\section{Tumor weight}

Tumors were removed and weighed when mice were sacrificed at the end of experiments.

\section{Data extraction}

The details were extracted from the included studies independently by two authors (J.L.C. and Y.M.L.) in this meta-analysis, which included first author name, publication year, information of mice (strain, age and 
gender), number of mice in each group, method used to produce OS mouse model, how the abnormally expressed miRNA was corrected, and the primary measured outcomes. Data were collected by mean outcome and standard deviation (SD) for each comparison. All data showed by graphs only without numbers were estimated by GetData Graph Digitizer 2.24. A third reviewer (Y.P.Y.) determined any disagreements between the two reviewers.

\section{Evaluation of methodological quality in the individual study}

There are no established dependable and valid tools for the judgment of the methodological quality in animal studies. STAIR (the initial Stroke Therapy Academic Industry Roundtable) was used to evaluate the reporting and design quality of the included studies, which includes: 1) sample-size calculation; 2) inclusion and exclusion criteria; 3) randomization; 4) allocation concealment; 5) reporting of animals excluded from analysis; 6) blinded assessment of outcome; and 7) reporting potential conflicts of interest and study funding [87], and was updated by the STAIR group in 2009 based on the Recommendations for Ensuring Good Scientific Inquiry for America. Two authors (Q.S. and Y.J.W.) assessed the methodological qualities in all included studies and presented as a yes or no. The "unclear" signified that the methodological quality was not clear.

\section{Statistical analysis}

Data were pooled together for analysis if outcomes were reported by 2 or more studies. Two primary outcomes (tumor volume and tumor weight) were analyzed individually. We conducted pair-wise meta-analysis for studies, which directly compared the influence on tumor growth between corrected miRNAs expression and the control (abnormally expressed miRNAs), to determine the pooled relative effect of each intervention compared with the other effect for each measurement outcome of interest, and the mean differences (MDs) of the post-intervention values from the different interventions were determined. We adopted the post-intervention values in meta-analysis derived from the baseline values being comparable between target miRNA group and mimic miRNA or placebo control group, as specified by a Cochrane review [88].

Final consequences from the studies to evaluate differences between the intervention and control group were analyzed by the REVIEW MANAGER 5.1.2 software offered by the Cochrane Collaboration, and $\mathrm{I}^{2}$ was calculated to evaluate the heterogeneity. Heterogeneity was existed if the $p$ value was less than 0.10 by the chisquare $\left(\mathrm{x}^{2}\right)$ test. If the $\mathrm{I}^{2}$ value was greater than $50 \%$, the results were thought to have a high level of heterogeneity
[88]. Clinically and statistically homogeneous studies should be pooled using the fixed-effects model [88]. Clinically homogeneous and statistically heterogeneous studies should be pooled using the random-effects model [88]. When same outcomes were measured using different instruments across studies, we used a standardized mean difference (SMD) in the meta-analysis to combine continuous data.

\section{ACKNOWLEDGMENTS}

Grant support: This study was supported by grants from 1) National Nature Science Foundation (81373667), 2) TCM scientific research fund of Shanghai Municipal Commission of Health and Family Planning (2014JQ031A), 3) the Program for Innovative Research Team in Ministry of Science and Technology (2015RA4002).

\section{CONFLICT OF INTEREST}

No conflict of interest was declared.

\section{REFERENCES}

1. Ta HT, Dass CR, Choong PF and Dunstan DE. Osteosarcoma treatment: state of the art. Cancer metastasis reviews. 2009; 28:247-263.

2. Miao J, Wu S, Peng Z, Tania M and Zhang C. MicroRNAs in osteosarcoma: diagnostic and therapeutic aspects. Tumour biology. 2013; 34:2093-2098.

3. Suzuki M, Wada H, Yoshino M, Tian L, Shigematsu H, Suzuki H, Alaa M, Tamura H, Fujiwara T, Nagato K, Motohashi S, Moriya Y, Hoshino H, et al. Molecular characterization of chronic obstructive pulmonary diseaserelated non-small cell lung cancer through aberrant methylation and alterations of EGFR signaling. Annals of surgical oncology. 2010; 17:878-888.

4. Ogino S, Nosho K, Irahara N, Shima K, Baba Y, Kirkner GJ, Mino-Kenudson M, Giovannucci EL, Meyerhardt JA and Fuchs CS. Negative lymph node count is associated with survival of colorectal cancer patients, independent of tumoral molecular alterations and lymphocytic reaction. The American journal of gastroenterology. 2010; 105:420433.

5. Croyle MA. Long-term virus-induced alterations of CYP3A-mediated drug metabolism: a look at the virology, immunology and molecular biology of a multi-faceted problem. Expert opinion on drug metabolism \& toxicology. 2009; 5:1189-1211.

6. $\quad$ Sung MT, Zhang S, Lopez-Beltran A, Montironi R, Wang M, Davidson DD, Koch MO, Cain MP, Rink RC and Cheng L. Urothelial carcinoma following augmentation cystoplasty: an aggressive variant with distinct clinicopathological characteristics and molecular genetic 
alterations. Histopathology. 2009; 55:161-173.

7. Griffin CA, Morsberger L, Hawkins AL, Haddadin M, Patel A, Ried T, Schrock E, Perlman EJ and Jaffee E. Molecular cytogenetic characterization of pancreas cancer cell lines reveals high complexity chromosomal alterations. Cytogenetic and genome research. 2007; 118:148-156.

8. Vauhkonen H, Heino S, Myllykangas S, Lindholm PM, Savola S and Knuutila S. Etiology of specific molecular alterations in human malignancies. Cytogenetic and genome research. 2007; 118:277-283.

9. Rich TA. Cancer symptom complexes related to alterations in molecular circadian axis signaling. Conference proceedings. 2006; 1:171-172.

10. Bartel DP. MicroRNAs: genomics, biogenesis, mechanism, and function. Cell. 2004; 116:281-297.

11. Lewis BP, Burge CB and Bartel DP. Conserved seed pairing, often flanked by adenosines, indicates that thousands of human genes are microRNA targets. Cell. 2005; 120:15-20.

12. Volinia S, Calin GA, Liu CG, Ambs S, Cimmino A, Petrocca F, Visone R, Iorio M, Roldo C, Ferracin M, Prueitt RL, Yanaihara N, Lanza G, et al. A microRNA expression signature of human solid tumors defines cancer gene targets. Proceedings of the National Academy of Sciences of the United States of America. 2006; 103:2257-2261.

13. Lu J, Getz G, Miska EA, Alvarez-Saavedra E, Lamb J, Peck D, Sweet-Cordero A, Ebert BL, Mak RH, Ferrando AA, Downing JR, Jacks T, Horvitz HR and Golub TR. MicroRNA expression profiles classify human cancers. Nature. 2005; 435:834-838.

14. Asangani IA, Rasheed SA, Nikolova DA, Leupold JH, Colburn NH, Post S and Allgayer H. MicroRNA-21 (miR21) post-transcriptionally downregulates tumor suppressor Pdcd4 and stimulates invasion, intravasation and metastasis in colorectal cancer. Oncogene. 2008; 27:2128-2136.

15. Esquela-Kerscher A and Slack FJ. Oncomirs - microRNAs with a role in cancer. Nature reviews Cancer. 2006; 6:259269.

16. Calin GA and Croce CM. MicroRNA signatures in human cancers. Nature reviews Cancer. 2006; 6:857-866.

17. Osaki M, Takeshita F, Sugimoto Y, Kosaka N, Yamamoto Y, Yoshioka Y, Kobayashi E, Yamada T, Kawai A, Inoue $\mathrm{T}$, Ito $\mathrm{H}$, Oshimura $\mathrm{M}$ and Ochiya T. MicroRNA-143 regulates human osteosarcoma metastasis by regulating matrix metalloprotease-13 expression. Molecular therapy. 2011; 19:1123-1130.

18. Huang CY, Beer TM, Higano CS, True LD, Vessella R, Lange PH, Garzotto M and Nelson PS. Molecular alterations in prostate carcinomas that associate with in vivo exposure to chemotherapy: identification of a cytoprotective mechanism involving growth differentiation factor 15. Clin Cancer Res. 2007; 13:5825-5833.

19. Hu H, Zhang Y, Cai XH, Huang JF and Cai L. Changes in microRNA expression in the MG-63 osteosarcoma cell line compared with osteoblasts. Oncology letters. 2012; 4:10371042.

20. Liu LH, Li H, Li JP, Zhong H, Zhang HC, Chen J and Xiao T. miR-125b suppresses the proliferation and migration of osteosarcoma cells through down-regulation of STAT3. Biochemical and biophysical research communications. 2011; 416:31-38.

21. van der Deen M, Taipaleenmaki H, Zhang Y, Teplyuk NM, Gupta A, Cinghu S, Shogren K, Maran A, Yaszemski MJ, Ling L, Cool SM, Leong DT, Dierkes C, et al. MicroRNA$34 \mathrm{c}$ inversely couples the biological functions of the runt-related transcription factor RUNX2 and the tumor suppressor p53 in osteosarcoma. The Journal of biological chemistry. 2013; 288:21307-21319.

22. Fan LS, Z; Wu, Q; Wei, Y; Yu, X. MicroRNA145 inhibits proliferation and apoptosis of osteosarcoma cells. China Oncology. 2012; 22:5.

23. Almog N, Ma L, Schwager C, Brinkmann BG, Beheshti A, Vajkoczy P, Folkman J, Hlatky L and Abdollahi A. Consensus micro RNAs governing the switch of dormant tumors to the fast-growing angiogenic phenotype. PloS one. 2012; 7:e44001.

24. Huang G, Nishimoto K, Zhou Z, Hughes D and Kleinerman ES. miR-20a encoded by the miR-17-92 cluster increases the metastatic potential of osteosarcoma cells by regulating Fas expression. Cancer Res. 2012; 72:908-916.

25. Sun Z, Zhang T, Hong H, Liu Q and Zhang H. miR202 suppresses proliferation and induces apoptosis of osteosarcoma cells by downregulating Gli2. Molecular and cellular biochemistry. 2014; 397:277-283.

26. Jones KB, Salah Z, Del Mare S, Galasso M, Gaudio E, Nuovo GJ, Lovat F, LeBlanc K, Palatini J, Randall RL, Volinia S, Stein GS, Croce CM, Lian JB and Aqeilan RI. miRNA signatures associate with pathogenesis and progression of osteosarcoma. Cancer Res. 2012; 72:18651877.

27. Wu ZL, X; Yang, S. MiR-21 affects osteosarcoma cell proliferation. China Oncology. 2010; 20:6.

28. Wu Z. Effeets of microRNA-21on osteosarcoma biological behaviors. 2011.

29. Yuan J, Lang J, Liu C, Zhou K, Chen L and Liu Y. The expression and function of miRNA-451 in osteosarcoma. Med Oncol. 2015; 32:324.

30. Tiram G, Segal E, Krivitsky A, Shreberk-Hassidim R, Ferber S, Ofek P, Udagawa T, Edry L, Shomron N, Roniger M, Kerem B, Shaked Y, Aviel-Ronen S, et al. Identification of Dormancy-Associated MicroRNAs for the Design of Osteosarcoma-Targeted Dendritic Polyglycerol Nanopolyplexes. ACS nano. 2016; 10:2028-2045.

31. Chen J, Zhou J, Chen X, Yang B, Wang D, Yang P, He X and Li H. miRNA-449a is downregulated in osteosarcoma and promotes cell apoptosis by targeting BCL2. Tumour biology. 2015; 36:8221-8229.

32. Zhou X, Wei M and Wang W. MicroRNA-340 suppresses 
osteosarcoma tumor growth and metastasis by directly targeting ROCK1. Biochemical and biophysical research communications. 2013; 437:653-658.

33. Yan KG, J; Yang, T; Ma, Q; Qiu, X; Fan, Q; Ma, B. MicroRNA-34a Inhibits the Proliferation and Metastasis of Osteosarcoma Cells Both In Vitro and In Vivo. PloS one. 2012; 7:11.

34. $\mathrm{Xu} \mathrm{Z}$ and Wang T. miR-214 promotes the proliferation and invasion of osteosarcoma cells through direct suppression of LZTS1. Biochemical and biophysical research communications. 2014; 449:190-195.

35. Xu G, Wang J, Jia Y, Shen F, Han W and Kang Y. MiR142-3p functions as a potential tumor suppressor in human osteosarcoma by targeting HMGA1. Cellular physiology and biochemistry. 2014; 33:1329-1339.

36. Wu X, Zhong D, Gao Q, Zhai W, Ding Z and Wu J. MicroRNA-34a inhibits human osteosarcoma proliferation by downregulating ether a go-go 1 expression. International journal of medical sciences. 2013; 10:676-682.

37. Wang J, Xu G, Shen F and Kang Y. miR-132 targeting cyclin E1 suppresses cell proliferation in osteosarcoma cells. Tumour biology. 2014; 35:4859-4865.

38. Song L, Yang J, Duan P, Xu J, Luo X, Luo F, Zhang Z, Hou T, Liu B and Zhou Q. MicroRNA-24 inhibits osteosarcoma cell proliferation both in vitro and in vivo by targeting LPAATbeta. Archives of biochemistry and biophysics. 2013; 535:128-135.

39. Li G, Cai M, Fu D, Chen K, Sun M, Cai Z and Cheng B. Heat shock protein $90 \mathrm{~B} 1$ plays an oncogenic role and is a target of microRNA-223 in human osteosarcoma. Cellular physiology and biochemistry. 2012; 30:1481-1490.

40. Ji F, Zhang H, Wang Y, Li M, Xu W, Kang Y, Wang Z, Cheng P, Tong D, Li C and Tang H. MicroRNA-133a, downregulated in osteosarcoma, suppresses proliferation and promotes apoptosis by targeting Bcl-xL and Mcl-1. Bone. 2013; 56:220-226.

41. Zhang H. microRNA-143, down-regulated in osteosarcoma, promotes apoptosis and suppresses tumorigenicity by targeting Bcl-2. Oncology reports. 2010; 24.

42. Han K, Zhao T, Chen X, Bian N, Yang T, Ma Q, Cai C, Fan Q, Zhou Y and Ma B. microRNA-194 suppresses osteosarcoma cell proliferation and metastasis in vitro and in vivo by targeting $\mathrm{CDH} 2$ and IGF1R. International journal of oncology. 2014; 45:1437-1449.

43. Fujiwara T, Katsuda T, Hagiwara K, Kosaka N, Yoshioka Y, Takahashi RU, Takeshita F, Kubota D, Kondo T, Ichikawa H, Yoshida A, Kobayashi E, Kawai A, Ozaki $\mathrm{T}$ and Ochiya $\mathrm{T}$. Clinical relevance and therapeutic significance of microRNA-133a expression profiles and functions in malignant osteosarcoma-initiating cells. Stem Cells. 2014; 32:959-973.

44. Cheng C, Chen ZQ and Shi XT. MicroRNA-320 inhibits osteosarcoma cells proliferation by directly targeting fatty acid synthase. Tumour biology. 2014; 35:4177-4183.
45. Chen L, Wang Q, Wang GD, Wang HS, Huang Y, Liu $\mathrm{XM}$ and Cai XH. miR-16 inhibits cell proliferation by targeting IGF1R and the Raf1-MEK1/2-ERK1/2 pathway in osteosarcoma. FEBS letters. 2013; 587:1366-1372.

46. Zhou J, Wu S, Chen Y, Zhao J, Zhang K, Wang J and Chen S. microRNA-143 is associated with the survival of ALDH1+CD133+ osteosarcoma cells and the chemoresistance of osteosarcoma. Exp Biol Med (Maywood). 2015; 240:867-875.

47. Zhao Y, Tu MJ, Yu YF, Wang WP, Chen QX, Qiu JX, Yu $\mathrm{AX}$ and $\mathrm{Yu}$ AM. Combination therapy with bioengineered miR-34a prodrug and doxorubicin synergistically suppresses osteosarcoma growth. Biochem Pharmacol. 2015; 98:602-613.

48. Xu M, Jin H, Xu CX, Sun B, Song ZG, Bi WZ and Wang Y. miR-382 inhibits osteosarcoma metastasis and relapse by targeting Y box-binding protein 1. Molecular therapy. 2015; 23:89-98.

49. Wang XH, Cai P, Wang MH and Wang Z. microRNA25 promotes osteosarcoma cell proliferation by targeting the cellcycle inhibitor p27. Molecular medicine reports. 2014; 10:855-859.

50. Wang X, Sun J, Fu C, Wang D and Bi Z. MicroRNA-214 regulates osteosarcoma survival and growth by directly targeting phosphatase and tensin homolog. Molecular medicine reports. 2014; 10:3073-3079.

51. Tian K, Di R and Wang L. MicroRNA-23a enhances migration and invasion through PTEN in osteosarcoma. Cancer gene therapy. 2015; 22:351-359.

52. Sun X, Geng X, Zhang J, Zhao H and Liu Y. miR-155 promotes the growth of osteosarcoma in a HBP1-dependent mechanism. Molecular and cellular biochemistry. 2015; 403:139-147.

53. Sun B, Yang M, Li M and Wang F. The microRNA-217 functions as a tumor suppressor and is frequently downregulated in human osteosarcoma. Biomedicine \& pharmacotherapy $=$ Biomedecine $\&$ pharmacotherapie. 2015; 71:58-63.

54. Luo XJ, Tang DG, Gao TL, Zhang YL, Wang M, Quan ZX and Chen J. MicroRNA-212 inhibits osteosarcoma cells proliferation and invasion by down-regulation of Sox4. Cellular physiology and biochemistry. 2014; 34:2180-2188.

55. Liu W, Xu G, Liu H and Li T. MicroRNA-490-3p regulates cell proliferation and apoptosis by targeting HMGA2 in osteosarcoma. FEBS letters. 2015; 589:3148-3153.

56. Kawano M, Tanaka K, Itonaga I, Ikeda S, Iwasaki $\mathrm{T}$ and Tsumura H. microRNA-93 promotes cell proliferation via targeting of PTEN in Osteosarcoma cells. Journal of experimental \& clinical cancer research. 2015; 34:76.

57. Iwasaki T, Tanaka K, Kawano M, Itonaga I and Tsumura H. Tumor-suppressive microRNA-let-7a inhibits cell proliferation via targeting of E2F2 in osteosarcoma cells. International journal of oncology. 2015; 46:1543-1550.

58. He Y, Meng C, Shao Z, Wang H and Yang S. MiR-23a 
functions as a tumor suppressor in osteosarcoma. Cellular physiology and biochemistry. 2014; 34:1485-1496.

59. Ge L, Zheng B, Li M, Niu L and Li Z. MicroRNA-497 suppresses osteosarcoma tumor growth and. Oncology letters. 2016; 11:2207-2212.

60. Duan G, Ren C, Zhang Y and Feng S. MicroRNA-26b inhibits metastasis of osteosarcoma via targeting CTGF and Smad1. Tumour biology. 2015; 36:6201-6209.

61. Wei Wang XZ, Min Wei. MicroRNA-144 suppresses osteosarcoma growth and metastasis by targeting ROCK1 and ROCK2. Oncotarget. 2015; 6:12. doi: 10.18632/ oncotarget.3305.

62. Kang Han Xiang Chen NB, Baoan Ma, Tongtao Yang, Chengkui Cai,QingYu Fan, Yong Zhou and TingBao Zhao. MicroRNA profiling identifies MiR-195 suppresses osteosarcoma cell metastasis by targeting CCND1. Oncotarget. 2015; 6:15. doi: 10.18632/oncotarget.3560.

63. Jin J. miRNA-218 inhibits osteosarcoma cell migration and invasion by down-regulating of TIAM1, MMP2 and MMP9 2013.

64. Gao J. The role of miR-195 in metastasis of osteosarcoma and its mechanism. 2012.

65. Fan L. A dissertation submitted to Huazhong University of Science and Technology for the Degree of Doctor of Medicine 2013.

66. Garzon R, Marcucci G and Croce CM. Targeting microRNAs in cancer: rationale, strategies and challenges. Nature reviews Drug discovery. 2010; 9:775-789.

67. Liu C and Tang DG. MicroRNA regulation of cancer stem cells. Cancer research. 2011; 71:5950-5954.

68. Tsilidis KK, Panagiotou OA, Sena ES, Aretouli E, Evangelou E, Howells DW, Al-Shahi Salman R, Macleod MR and Ioannidis JP. Evaluation of excess significance bias in animal studies of neurological diseases. PLoS biology. 2013; 11:e1001609.

69. Moja L, Pecoraro V, Ciccolallo L, Dall'Olmo L, Virgili G and Garattini S. Flaws in animal studies exploring statins and impact on meta-analysis. European journal of clinical investigation. 2014; 44:597-612.

70. van der Worp HB, Howells DW, Sena ES, Porritt MJ, Rewell S, O'Collins V and Macleod MR. Can animal models of disease reliably inform human studies? PLoS medicine. 2010; 7:e1000245.

71. Perel P, Roberts I, Sena E, Wheble P, Briscoe C, Sandercock P, Macleod M, Mignini LE, Jayaram P and Khan KS. Comparison of treatment effects between animal experiments and clinical trials: systematic review. BMJ. 2007; 334:197.

72. Pound P, Ebrahim S, Sandercock P, Bracken MB and Roberts I. Where is the evidence that animal research benefits humans? BMJ. 2004; 328:514-517.

73. O'Collins VE, Macleod MR, Donnan GA, Horky LL, van der Worp BH and Howells DW. 1,026 experimental treatments in acute stroke. Annals of neurology. 2006;
59:467-477.

74. Landis SC, Amara SG, Asadullah K, Austin CP, Blumenstein R, Bradley EW, Crystal RG, Darnell RB, Ferrante RJ, Fillit H, Finkelstein R, Fisher M, Gendelman $\mathrm{HE}$, et al. A call for transparent reporting to optimize the predictive value of preclinical research. Nature. 2012; 490:187-191.

75. Rooke ED, Vesterinen HM, Sena ES, Egan KJ and Macleod MR. Dopamine agonists in animal models of Parkinson's disease: a systematic review and meta-analysis. Parkinsonism \& related disorders. 2011; 17:313-320.

76. Vesterinen HM, Sena ES, ffrench-Constant C, Williams A, Chandran $\mathrm{S}$ and Macleod MR. Improving the translational hit of experimental treatments in multiple sclerosis. Mult Scler. 2010; 16:1044-1055.

77. Currie GL, Delaney A, Bennett MI, Dickenson AH, Egan KJ, Vesterinen HM, Sena ES, Macleod MR, Colvin LA and Fallon MT. Animal models of bone cancer pain: systematic review and meta-analyses. Pain. 2013; 154:917-926.

78. Hirst TC, Vesterinen HM, Sena ES, Egan KJ, Macleod MR and Whittle IR. Systematic review and meta-analysis of temozolomide in animal models of glioma: was clinical efficacy predicted? British journal of cancer. 2013; 108:6471.

79. Frantzias J, Sena ES, Macleod MR and Al-Shahi Salman R. Treatment of intracerebral hemorrhage in animal models: meta-analysis. Annals of neurology. 2011; 69:389-399.

80. Amyere M, Dompmartin A, Wouters V, Enjolras O, Kaitila I, Docquier PL, Godfraind C, Mulliken JB, Boon LM and Vikkula M. Common somatic alterations identified in maffucci syndrome by molecular karyotyping. Molecular syndromology. 2014; 5:259-267.

81. Pittler MH, Abbot NC, Harkness EF and Ernst E. Location bias in controlled clinical trials of complementary/ alternative therapies. Journal of clinical epidemiology. 2000; 53:485-489.

82. J. H and Chapter 8: Assessing risk of bias in included studies. Cochrane Handbook for Systematic Reviews of Interventions, Version 5.1. England: John Wiley \& Sons Ltd;2011:187-241

83. Higgins JP. Commentary: Heterogeneity in metaanalysis should be expected and appropriately quantified. International journal of epidemiology. 2008; 37:1158-1160.

84. Vesterinen HM, Sena ES, Egan KJ, Hirst TC, Churolov L, Currie GL, Antonic A, Howells DW and Macleod MR. Meta-analysis of data from animal studies: a practical guide. Journal of neuroscience methods. 2014; 221:92-102.

85. Low SA, Yang J and Kopecek J. Bone-targeted acidsensitive doxorubicin conjugate micelles as potential osteosarcoma therapeutics. Bioconjugate chemistry. 2014; 25:2012-2020.

86. Zhang Y, Sun S, Chen J, Ren P, Hu Y, Cao Z, Sun H and Ding Y. Oxymatrine induces mitochondria dependent apoptosis in human osteosarcoma MNNG/HOS cells 
through inhibition of PI3K/Akt pathway. Tumour biology. 2014; 35:1619-1625.

87. Hughes DP. Strategies for the targeted delivery of therapeutics for osteosarcoma. Expert opinion on drug delivery. 2009; 6:1311-1321.
88. Anninga JK, Gelderblom H, Fiocco M, Kroep JR, Taminiau $\mathrm{AH}$, Hogendoorn PC and Egeler RM. Chemotherapeutic adjuvant treatment for osteosarcoma: where do we stand? Eur J Cancer. 2011; 47:2431-2445. 